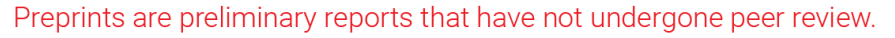 \\ They should not be considered conclusive, used to inform clinical practice, or referenced by the media as validated information. \\ Role of Exosome in Delivery of MicroRNA Into Cells As a Major Tool of Disease Resistance
}

\section{Rachayeeta Ray}

Jadavpur University Faculty of Science

Debalina Bhattacharya

Maulana Azad College

Parimal Karmakar ( $\sim$ pkarmakar_28@yahoo.co.in )

Jadavpur University Faculty of Science https://orcid.org/0000-0002-9423-9906

\section{Research Article}

Keywords: Biomarker, Cancer, Diseases, Downregulation, Exosomes, miRNA, Upregulation

Posted Date: October 20th, 2021

DOl: https://doi.org/10.21203/rs.3.rs-974492/v1

License: (c) (i) This work is licensed under a Creative Commons Attribution 4.0 International License. Read Full License 


\section{Abstract}

Exosomes are small-sized extracellular vesicles. Their size ranges from 30-150 nm and contains proteins, lipids, nucleic acids along other bioactive molecules. It is now also considered as communicating mediators between cells where their content varies with the microenvironment of the cells which may ultimately change numerous physiological and pathological functions of the cells. Because of their small size, safety, biocompatibility, biorecognition, high stability, target specificity, and ability to cross the bloodbrain barrier, the exosomes have recently gained attention as a potential nano delivery system. However, the focus of this review article is to cover the latest updates regarding the role of exosomal delivery of different micro RNAs which have an important role in disease control. Micro RNAs, which are of utmost importance as an exosomal cargo, has been reported to show both positive and negative impact on the cell it is targeted or delivered to.

\section{Introduction}

Exosomes are one type of small extracellular vesicles secreted by all types of cells. Exosomes remain surrounded by bilayer lipid membranes (Duan et al., 2021). The extracellular vesicles are of generally three types, Exosomes (30-150 nm), Microvesicles (50-1000 nm), and Apoptotic bodies (50-5000 nm) (Wu et.al, 2017). Exosomes are reported to be carrying several types of cargo depending on the cell types and conditions from where they are generated. Exosomes are found to be less immunogenic, as well as non toxic to the recipient cells (O'Loughlin et. al, 2012). This makes them a potential carrier of other therapeutic agents to treat different types of diseases in a recipient cell. Exosomes fuse with cells other than their parent cell and release their content into that cell. Thus, they play an important role in cell-tocell communication (Wu et. al, 2017). Hence, exosomes can be used in both treatments of different diseases as well as in the induction and progression of the tumorigenic process.

While being released from cells, exosomes carry some components from the cells such as proteins, mRNA, micro RNA, siRNA, DNA, lipids, etc. (Duan et al., 2021). The type of cargos it carries varies depending upon its origin, physiological and pathological state as well as the explicit cellular site (Duan et al., 2021). Proteins that are found in exosomes include platelet-derived growth factor receptor, lactadherin, transmembrane proteins, and lysosome-associated membrane protein-2B, membrane transport and fusion proteins such as annexins, flotillins, GTPases, heat shock proteins (Hsc70), tetraspanins (e.g CD63, CD81, CD9, etc.), proteins involved in multivesicular body biogenesis, as well as lipid-related proteins and phospholipases (Fig.1). These proteins can therefore be used as biomarkers for isolation and quantification of exosomes ( $\mathrm{Li}$ et. al, 2017). Exosomes can attach to target cells by the surface adhesion proteins and vector ligands (tetraspanins, integrins, etc.), and deliver their payload to target cells.

\section{Exosomal miRNA and its function}


Several studies reported that miRNA carries via exosome from a parental cell to a target cell can play an immensely positive role in disease control and different miRNA families are responsible for repressing different diseases when delivered via exosomes (Barile and Vassalli, 2017). The functions of exosomal miRNAs can be generally classified into two types. One is the conventional function, i.e., miRNAs perform negative regulation and confer characteristic changes in the expression levels of target genes and may be responsible for disease development. The other is the building of defence mechanisms against different diseases. Till now there are several miRNAs reported as a controversial role in both disease development as well as in disease prevention mechanisms. Based on these two functions we have selected ten miRNAs for this review article.

\section{Role of different miRNAs in disease development and prevention mechanisms against diseases.}

The miRNAs are the key elements of the regulation of many diseases. This is due to their exclusive property of binding to the $3^{\prime}$ UTR region of the target messenger RNA, which eventually results in posttranscriptional down-regulation of the expression of that gene (Haug et al, 2015). For this, sometimes the miRNAs cause the development of the disease by silencing a gene that may act as a suppressor of the disease. Such as, miR-128, which targets PPARY (peroxisome proliferator-activated receptor-gamma) leading to the development of Alzheimer's disease in mice (Liu et. al, 2019). On the other hand, they may sometimes act as a suppressor of a gene that may be associated with the development of the disease. For example, miR-27a-5p and miR-34b-3p were found to act as tumor-suppressor micro RNAs in small cell lung cancer, targeting topoisomerase 2 alpha (TOP2A), maternal embryonic leucine zipper kinase (MELK), centromere protein $\mathrm{F}$ (CENPF), and SRY-box 1 (SOX1), which are identified as oncogenes (Mizuno et al, 2017). Thus, exosomal delivery of these various micro RNAs plays a very crucial role in disease regulation as exosomes are recognized as one of the media of communications between two or more neighbouring cells (Fig.2).

Micro RNA-21: The micro RNA 21 (miR-21) has been shown to play a pivotal role in the development as well as disease defence. Several studies have revealed that exosomal miR-21 has a role in the development of chemoresistance in different carcinomas like neuroblastoma, ovarian cancer, gastric cancer, pancreatic cancer, hepatocellular carcinoma, etc (Challagundla et. al, 2015). Exosomes isolated from ovarian cancer-associated fibroblasts (CAFs) and cancer-associated adipocytes (CAAs), carry miRNA-21 which could not only increase chemoresistance to paclitaxel through downregulating their direct target Apoptotic protease activating factor 1 (APAF1), but also could suppress the apoptosis of ovarian cancer cells (Yeung et al., 2016). It has been seen that transfecting cisplatin-resistant oral squamous cell carcinoma (OSCC) derived exosomes can transform non-resistant parental OSCCs into resistance to cisplatin targeting phosphatase and tensin homolog (PTEN) and programmed cell death 4 (PDCD4) (Liu et. al, 2017). Transfection of miRNA-21 loaded exosomes into human gastric cancer cell line acted as a promoter of the tumor by targeting the PDCD 4 gene, causing inhibition of PDCD4 expression and hence apoptosis in gastric cancer cells (Wang et al., 2015). 
Environmental factors are also found to be effective in disease development via the exosomal transfer of miRNAs. Exosomes derived from arsenite-transformed human bronchial epithelial (HBE) cells can deliver miRNA-21 to normal HBE cells resulting in their transformation into malignant cells (Xu et. al, 2015).

The miRNA-21 has been found to play a progressive role in breast cancer development (Hannafon et. al, 2016). Such as it was found to be present in extracellular vesicles derived from serum-deprived human mesenchymal stem/stromal cells (SD-MSCs), playing a tumor-promoting role in breast cancer (MCF-7) or osteosarcoma (KHOS) cells (Vallabhaneni et. al, 2015). Exosomes derived from Cancer-associated fibroblasts (CAFs) carry mir-21 which is mainly responsible for a significant increase in capacity of the breast cancer cells to form mammospheres, increasing stem cell and epithelial-mesenchymal transition (EMT) markers, and anchorage-independent growth of the cells (Donnarumma et. al, 2017).

The gastric cancer cell-derived exosomes were found to be carrying miR-21-5p, which is considered as the guide strand of miR-21, that prompted mesothelial-to-mesenchymal transition of peritoneal mesothelial cells rendering peritoneal metastasis ( $\mathrm{Li}$ et. al, 2018). A significantly enhanced expression of miR-21 is considered as a marker for the detection of aggressiveness of pancreatic cancer (Goto et. al, 2018). It was observed that level of exosomal miR-21 was higher in hepatocellular carcinoma cell-derived exosomes and when hepatic stellate cells (HSC) were treated with these exosomes, they were activated through the PTEN/PDK1/Akt pathway, converting HSCs into cancer-associated fibroblast cells, that promotes angiogenesis, and this was regulated by miR-21 (Zhou et. al, 2018). Bioinformatics analysis revealed that miR-21 owned binding sites on PTEN, PTENp1, and TET (ten-eleven translocation) family proteins (TET1, TET2, and TET3), decreased PTENp1 and PTEN expression, thereby significantly promoting the proliferation of hepatocellular carcinoma cells (HCC), inhibiting their apoptosis, as well as promoting cell invasion (Cao et. al, 2019). In the same study, it was seen that the direct cecal coimplantation of colorectal cancer cells (SW620) with MRC5 fibroblasts, stably overexpressed miR-21 and as a result, there was a greater amount and size of metastatic tumor accumulation in the liver in an orthotopic colorectal cancer model, and it was supported by histological analysis exhibiting the presence of colorectal adenocarcinoma in the liver metastases (Bhome et. al, 2017). In patients with TNM (Tumor Nodes and Metastasis) stage of colorectal cancer miR-21, which was upregulated in the exosomes, showed a significant association with liver metastasis and TNM stage, also worsening the overall survival rates and disease-free survival rates of the patients (Tsukamoto et. al, 2017). When packed into M2 macrophage-derived exosomes (MDE), miR-21a-5p shows a high expression level and promotes migration and invasion of colorectal cancer cells by downregulating BRG1 expression when shuttled from M2 macrophages to colorectal cancer cells via exosomes (Lan et. al, 2019).

The miR-21 exhibited a 1.318-fold increase in the urinary exosomes from renal fibrosis patients compared to the controls also showing a significantly positive relationship with the tubulointerstitial damage index in the disease cases, suggesting them to be an important diagnostic tool in the diagnosis of the disease (Lv et. al, 2018). A miRNA profiling of urinary exosomes in active lupus nephritis patients showed upregulated expression of miR-21, which played an important role in increasing the synthesis of profibrotic molecules which in turn affects renal fibrogenesis (Solé et. al, 2019). On the other hand, in 
another study, a down-regulation of miR-21 was observed in urinary exosomes of active lupus nephritis patients concerning inactive ones. It had a negative correlation with both protein leakages and glomerular filtration rate (Tangtanatakul et. al, 2019). A remarkably interesting finding was shown that Endometrium mesenchymal stem cell (EnMSCs) derived exosomal miR-21 when delivered to infarcted rat myocardium, it acts as a principal effector of cardioprotection by contributing to the enhanced paracrine activity of EnMSCs, involving reduced expression of PTEN and increased phosphorylation of Akt in the exosome-treated target cells (Wang et. al, 2016). Primary human TAM (Tumor-associated Macrophages)-derived exosomes were enriched with miRNA-21-5p, which synergistically induced Treg/Th17 cell imbalance by targeting STAT3 directly in CD4p T cells, which in turn generates an immune-suppressive microenvironment facilitating the progression of epithelial ovarian cancer (Zhou et. al, 2018).

This micro-RNA also exhibited some disease-developing characteristics in bone metastases cases. A miRNA profiling of human osteosarcoma cells-derived exosomes revealed that the metastatic osteosarcoma cell (SAOS2) derived exosomes contained a 3 fold higher level of miR-21-5p than the nonmetastatic osteosarcoma cell (MG63) derived exosomes. Also, that may be due to this high content of miR-21-5p in the SAOS2 exosomes, they act as paracrine agents and could induce metastatic behaviour of the osteosarcoma cells by suppressing the expression of apoptotic genes (Jerez et. al, 2019). Lung adenocarcinoma cell-derived exosomes enriched with miR-21 were reported to promote osteoclastogenesis, by suppressing Programmed cell death protein 4 (PDCD4) after being transported into osteoclast progenitor cells (Xu et. al, 2018).

Antisense miRNA oligonucleotides against miR-21 (AMO-21) caused declination of the tumor size of the glioblastoma rat model by promoting the expression of tumor-suppressive PTEN and PDCD4 (Kim et. al, 2020).

The role of this miR-21 is remarkably interesting in the case of cardiac diseases. The role of this miRNA is mostly protective towards cardiac diseases. Being able to better survive in ischemic myocardium, induced pluripotent stem cell-derived exosomes were used in a study to treat myocardial disease. It was seen that these exosomes contain a high amount of miR-21 and when they are transported into cardiomyocytes, they result in the inhibition of cardiomyocyte apoptosis by suppressing the expression of caspase 3 protein (Wang et. al, 2015). MiR-21 was significantly upregulated in exosomes derived from oxidative stress-induced cardiac progenitor cells. The expression of this micro RNA seemed to be downregulated in cardiomyocytes under oxidative stress but regained their expression when these cardiomyocytes were treated with the Cardiac Progenitor Cells (CPC)-derived exosomes. Not only that but this miRNA results in a decrease of caspase3 and PDCD4, leading to the inhibition of apoptosis of the cardiomyocytes (Xiao et. al, 2016). Delivery of Mesenchymal stem cell-derived exosomes carrying highly expressed miR-21-5p, to cardiomyocytes (H9c2), exhibit protective effects by preventing cardiac cell death from oxygen-glucose deprivation, basically by targeting and downregulating pro-apoptotic gene products, such as PDCD4, PTEN, Peli1 and FasL (Luther et. al, 2018). Despite its protective activities in cardiac cases, it was seen that miR-21-3p, which is the passenger strand of miR-21, was present in an enriched amount in the 
exosomes derived from nicotine-treated macrophages, stimulated the development of atherosclerosis and induced migration of vascular smooth muscle cells by targeting PTEN (Zhu et. al, 2019).

This miRNA was also found to have a specific role in viral diseases. Human papilloma viruses (HPVs) are one of the causative agents of cervical cancer. According to an analysis, the upregulation of miR-21-5p in HPV-infected cervical cancer cell-derived exosomes was dependent upon the silencing of the E6/E7 oncogene (Honegger et. al, 2015). A lower expression of miR-21 in plasma-derived exosomes seemed to be associated with the declination of CD4 T cells in HIV-1-infected elite controllers (Ruiz-de-Leo'n et. al, 2019).

All the above, studies were efficient in suggesting the differential role of the exosomal miR-21 family, in the development or/and the treatment of different diseases.

Micro RNA-19: The role of the miR-19 family is seen most significantly in colorectal carcinoma cases and identified as a potential marker for this disease (Eylem et. al, 2020). Not only in cases of colorectal cancer but also the differential expression of exosomal miR-19 was observed in patients with gastric cancer (Wang et. al, 2017), pancreatic cancer (Zou et. al, 2019), bladder cancer (Amuran et. al, 2020) and in patients with chronic lymphocytic leukemia (CLL) (Jurj et. al, 2018). Therefore, exosomal miR-19 can act as a potential diagnostic marker for these cancers too. Additionally, miR19a exhibit a disease-resistant role in cardiac diseases. miR-19a reduced the expression of apoptosis regulatory genes PTEN and BIM (Bcl2/11), directly participating in the regeneration of the myocardium, thus providing cardio protection in post-ischemic conditions (Yu et. al, 2015).

Exosomal miR-19b has an interesting role in the recovery of diabetic neuropathy (Fan et. al, 2020), Parkinson's disease (Cao et. al, 2017) and Alzheimer's disease (Gui et. al, 2015) and be a potential biomarker of these diseases.

Micro RNA-let-7 group: The infection of the Japanese Encephalitis virus, resulted in an increase of let$7 \mathrm{a} / \mathrm{b}$ in the microglia-derived exosomes. This elevated amount of let-7a/b, by collaborating with TLR7 and NOTCH signaling pathway increased the secretion of TNFa from microglia. Not only that, but these miRNAs also promoted neuronal damage by activating caspase, a mediator of inflammation and apoptosis (Mukherjee et. al, 2019). Although, this group of miRNAs has been also found to show the beneficiary effect on neuron-related diseases. As, in a certain study, it was found that mouse mesenchymal stem cell-derived exosomes contained highly expressed miRNAs including let-7a, let7e, and let-7d, which downregulated TLR4/NF-KB signaling pathway, the main element involved in diabetic peripheral neuropathy and hence contribute to improvement of neurovascular function and recovery from the disease (Fan et. al, 2020).

Cigarette smoke is the main causative agent of chronic obstructive pulmonary disease (COPD). The primary human lung microvascular endothelial cells release exosomes (termed as circulating endothelial microparticles i.e., EMPs) enriched with several different micro RNAs including let-7d, which significantly 
increased upon exposure to cigarette smoke. It was assumed in this study, that the uptake of these exosomes by distant endothelial cells may inflect their phenotype, thus contributing to the development of COPD (Serban et. al, 2016). On the other hand, the downregulation of let-7a-5p, in the exosomes isolated from venous blood of lung adenocarcinoma patients, alongside, an upregulation of BCL2L1, were responsible for the poor survival of the patients (Zhang et. al, 2018). Exosomes derived from menstrual blood-derived stem cells (MenSCs) contained miR let-7, which by being transported into alveolar epithelial cells suppress the activation of Reactive Oxygen Species (ROS) and Mitochondrial DNA (mtDNA) damage by regulating NLRP3 signaling, using LOX1 as a target and thus improved the damaged condition of the injured lung epithelial cells, exhibiting a protective effect on lung fibrosis (Sun et. al, 2019).

In cardiac disease-related cases, this miRNA shows positive contribution, playing a role as disease therapeutic. The transfer of pericardial fluid derived exosomal let-7b-5p, to the endothelial cells, results in vascular repair. Being a pro-angiogenic miRNA, let-7b-5p downregulated the anti-angiogenic gene TGFBR1, thus promoting post-ischemic angiogenesis (Beltrami et. al, 2017). The level of let-7i was found to be significantly increased in plasma exosomes of multiple sclerosis patients. This elevated amount of let-7i repressed Foxp3+ regulatory $T$ cells, which is the suppressor of the proliferation of inflammatory $T$ cells and thus helps in the development of this T-cell mediated autoimmune disease (Kimura et. al, 2018). The expressions of let-7d-5p and let7c-5p were found to be significantly reduced in exosomes of multiple myeloma patients than in those of unaffected individuals and it was assumed that this downregulation may alter the expression of IL-6, contributing to the progression of the disease (Zhang et. al, 2019).

In urinary exosomes of lupus nephritis patients, the level of let-7a was significantly downregulated during the disease outbreak. From the references of some previous studies and based on the outcomes of this study, it was predicted that this downregulation may have a contribution to the failure of epigenetic regulatory systems of the kidney (Tangtanatakul et. al, 2019). Cervical cancer caused by human papilloma viruses (HPVs) depends upon the expression of E6/E7 oncogene for the cancer progression. In an experiment, it was seen that the undisrupted expression of E6/E7 oncogene results in the increased expression of let-7d-5p in cervical cancer cell-derived exosomes, and the silencing of this oncogene leads to downregulation of exosomal let-7d-5p. This made clear that the expression of exosomal let-7d-5p was dependent upon the E6/E7 expression and this relationship between the two can be used for prediction and early diagnosis of cervical cancer (Honegger et. al, 2015). Interestingly, the miR-let-7f, which was highly expressed in umbilical mesenchymal stem cell-derived exosomes, could reduce the replication of hepatitis C virus RNAs (Qian et. al, 2016). In a study, tumor-derived exosomes (isolated from breast cancer cell line, 4T1) were modified with some micro RNAs, including let-7i, which could downregulate TGF- $\beta$, SOCS1, and KLRK1 mRNA expression, at the same time overexpressing IL-6, IL-17, IFNy, IL-1b, and TLR4 mRNA and boosted maturation of dendritic cells, changing the immune-suppressive nature of tumorderived exosomes into immune responsive one (Taghikhani et. al, 2018). 
Micro RNA-29: The micro RNA 29 family also deserves to be mentioned as it is one of those miRNAs who exhibit their disease developing as well as disease resistance potential for a variety of diseases. It has immense importance as a marker of advanced hepatocellular carcinoma (HCC). Exosomes isolated from HCC patient-derived cells (PDCs) showed an own regulation of mir-29b-3p, in the case of fast-growing PDCs, compared to slow-growing cells which improve overall survival. Hence this group of miRNAs acts as a potential biomarker for HCC cell metastasis (Yu et. al, 2019). Significantly low expression of miR-29c in HCC derived exosomes were also observed in a comparative study between hepatocellular carcinoma, Hepatitis B virus (HBV), and hepatocirrhosis patients (Lin and Zhang, 2019). However, this miRNA has been found to act against hepatitis $C$ virus $(\mathrm{HCV})$ infection in hepatocytes. TLR3-activated macrophages secrete exosomes that carried significantly increased level of miR-29a, miR-29b, and mir-29c and on treating HCV infected hepatocytes with exosomes containing miR-29 members, replication capacity of $\mathrm{HCV}$ is inhibited, which is reversed with miR-29 inhibitor. This indicates that the miR-29 family; in this case, acts as an anti-HCV agent (Zhou et. al, 2016). A high expression of miR-29a-3p was observed in exosomes isolated from oral squamous cell carcinoma cells (OSCC). This also resulted in the M2 subtype polarization of macrophages, reinforcing the proliferation and incursion of the OSCC cells (Cai et al, 2019).

There are several contributions of the miR-29 family in renal diseases also. A downregulation of miR-29c was observed in urinary exosomes of renal fibrosis patients and this was negatively associated with estimated glomerular filtration rate and tubulinterstitial damage index (Lv et. al, 2018). The primary human tumor-associated macrophage (TAM) derived exosomes showed an upregulation of hsa-miR-29a$3 p$. This was found to be responsible for Tregs/Th17 cells imbalance in $C D 4^{+} T$ cells obtained from mice model with metastasizing ovarian cancer. This imbalance of Tregs/Th17 cells is a vital factor associated with the overall survival of epithelial ovarian cancer patients. The transfer of exosomal hsa-miR-29a-3p caused suppression of STAT3 expression thus causing immunosuppression, which triggered the Tregs/Th17 cells imbalance and this, in turn, leads to the progression of Epithelial Ovarian Cancer (EOC) (Zhou et.al, 2018).

To observe the effect of the exosomal miR-29 family on age-related insulin resistance, an experiment was performed, where bone marrow mesenchymal stem cells (BM-MSCs) derived exosomes collected from aged mice showed a significantly increased level of miR-29b-3p, which was higher in aged mice compared to young mice. This correlation of increased expression of miR-29b-3p with increasing age was also observed in exosomes derived from human BM-MSCs, suggesting the association of miR-29b-3p activity with aging. Administration of these exosomes into insulin-sensitive mice model, resulted in the alleviation of insulin-mediated glucose uptake by the adipocytes and myocytes, by targeting SIRT1 mRNA in the insulin-sensitive mice model and thus created insulin resistance in them (Su et. al, 2019).

The inactivation of Matrix Metalloprotease 9 (MMP9) and thus improvement of cardiovascular functions during the onset of diabetes could be attained by the highest expression of miR-29b in exosomes isolated from cardiac tissues and serum of diabetic mice model (Chaturvedi et. al, 2015). In another investigation 
also, among some other miRNAs, the elevated expression of miR-29 in Mesenchymal stem cell-derived exosomes was found to play a cardioprotective role by arousing cardiomyocyte proliferation and inhibiting cardiac cell apoptosis (Shao et. al, 2017). Hence, it can be assumed that in the case of cardiac dysfunctions the exosomes carrying miR-29 play a disease-resisting role.

Glioma-derived exosomes exhibit expression of miR-29a due to hypoxic conditions. Transfer of this exosomal miRNA into myeloid-derived suppressor cells (MDSCs) induces their proliferation and activity by downregulation of $\mathrm{Hbp} 1$ and Prkar1a gene expressions, which leads to the development of an immunosuppressive microenvironment (Guo et. al, 2019).

Micro RNA-146 group: The exosomal miR-146 family also exhibits some cardioprotective functions as reported in some previous studies. Patients with heart failure were subjected to an experiment, where it was observed that the exosomes isolated from cardiomyocytes of the patients exhibited overexpression of miR-146a in response to inflammation resulted from the heart failure. Not only that, but this elevated exosomal miR-146a could debilitate this inflammation, functioning as a cardioprotective cargo of exosomes of patients with heart failure (Beg et. al, 2017). Exosomes isolated from miR-146a overexpressed adipose-derived stem cells could put down EGR1 thus recovering myocardial injury, as well as myocardial fibrosis and apoptosis after acute myocardial infarction in both rat models and hypoxiainduced cardio myoblast cells (H9c2) (Pan et. al, 2019). On the contrary, there are some studies where this exosomal miR-146 family has been found to play role in cardiac disease development. For example, exosome isolated from endothelial colony-forming cells (ECFCs) with coronary artery disease contained overexpressed miR-146a-5p and miR-146b-5p, which when suppressed, resulted in the build-up of migration and microtubule formation activity of those cells. Whereas, after being carried via exosomes, an elevation of these micro RNAs in healthy ECFCs brought about an inhibition of the normal migration and tube formation capacity of these healthy cells, by targeting Rho-related GTP-binding protein RHOJ (Chang et al, 2017). Exosomes isolated from Treponema pallidum showed high expression of miR-146a$5 p$, which by being transported into the endothelial cells, downregulated JAM-C expression and decreased trans endothelial movement of monocytes and endothelial permeability, and hence inhibited the recovery from the injury caused by Treponema pallidum (Hu et. al, 2020).

To investigate the role of exosomal miRNAs in systemic lupus erythematosus (SLE), urinary exosomes were isolated from patients, in which a significantly increased level of miR-146a was observed in the SLE patients with active lupus nephritis, compared to control and this significant increase was about 8 fold in case of SLE patients with inactive lupus nephritis. These observations indicated that miR-146a in urinary exosomes of SLE patients could be used as a marker to differentiate the SLE patients with active lupus nephritis from those without lupus nephritis (Perez-Hernandez $\mathrm{J}$ et. al, 2015). While, in another study, serum exosomes collected from SLE patients showed a significantly low expression of miR-146a. The delivery of these exosomes into the bone marrow mesenchymal stem cells (BM-MSC) lowered the level of miR-146a in them, leading to the increase of senescence of the BM-MSC by activating TRAF6/NF-K $\beta$ signaling pathway and this is a cause of SLE progression. Thus, lower expression of miR-146a in serum exosomes of SLE patients increased the senescence of BM-MSc, which was confirmed by observing the 
inhibition of BM-MSC senescence treated with SLE serum exosomal miR-146a mimic with its high expression (Dong et. al, 2019). Exosomes were isolated from the urine of hypertensive patients with and without albuminuria, and the level of miR-146a was found to be significantly low in the urinary exosomes of hypertensive patients with albuminuria compared to the hypertensive patients of the non-albuminuria group. Also, it was seen that the severity of albuminuria was associated with a lower expression of miR$146 a$ in the urine exosomes of the patients, suggesting that this micro RNA can serve as a promising marker for detecting renal injury by observing the intensity of albuminuria in the hypertensive patients (Perez Hernandez et. al, 2018).

Vaginal cell proliferation and survivability are associated with the healing of a vaginal injury. The exosomes isolated from human umbilical cord mesenchymal stem cell (hucMSC) seemed to exhibit an increased expression of miR-146a, which lead to increased proliferation and cell viability when hucMSC exosomes were transfected into vaginal epithelial cells. This observation marked the implementation of exosomal miR-146a in healing vaginal injury by regeneration of tissues in the vagina (Zhu et. al, 2019).

Human multiple myeloma cells exhibited overexpression of miR-146a. The transfer of this miRNA through MM cell-secreted exosomes into healthy mesenchymal stromal cells (MSCs) resulted in the secretion of cytokines and chemokines like CXCL1, CCL-5, IL6, IL-8, IP-10, and MCP-1 in the healthy MSCs. As a result of the significantly exalted expression of these cytokines and chemokines in the healthy MSCs, increased migration and proliferation of the multiple myeloma cells were observed (Veirman et. al, 2016). Exosomal expressions of miR-146a-5p and miR-146a-3p of trophoblast cells were stimulated by the antiphospholipid antibody. There was no effect seen in the secretion of IL-8 due to miR-146a-5p, while miR-146a-3p seemed to increase the IL8 secretion in the trophoblast cells. Incubating TLR8 dominantnegative trophoblast cells with normal trophoblast cells seemed to attenuate the IL-8 secretion implying that this exosomal miR-146a-3p mediated IL8 secretion was due to activation of TLR8, thus leading to the generation of inflammatory response in the trophoblast cells (Gysler et. al, 2016). Some studies are implying the direct contribution of exosomal miR-146a in disease defence. Dementia due to type 2 diabetes is a result of the aggregation of cellular prion proteins. In general, miR-146a was seen to be downregulated in brain endothelial cell-derived exosomes of type 2 diabetic mice with excessive expression of prion proteins. The binding of externally elevated exosomal miR-146a to prion proteins in the brain of Type 2 diabetic mice leads to its suppression and thus the revival of memory (Kalani et. al, 2017).

Exosomes isolated from chronic lymphocytic leukemia patients were found to contain a high amount of miR-146a, which they transferred into endothelial and mesenchymal stem cells stimulating the secretion of inflammatory cytokines in them and inflecting the surrounding stromal cells to exhibit characteristics of cancer-associated fibroblasts (Paggetti et. al, 2015). Conversely, upregulation of miR-146a in exosomes isolated from TNF-a treated human umbilical cord-derived mesenchymal stem cells lead to the amelioration of fibroblast activation and inflammatory response correlated with urethral fibrosis when taken up by the fibroblasts of TGF $\beta 1$ injected urethral stricture tissues (Liang et. al, 2019). A study 
conducted to observe the role of virus-infected cell-derived exosomes showed that incorporation of EV71 viral RNA along with miR-146a leads to the restraining of type I interferon response by the exosomal miR146a, resulting in increased replication of the viral RNA, as observed in several cell lines (Fu et. al, 2017).

The upregulation of miR-146a in the exosomes isolated from interleukin-1 $\beta$ treated human umbilical cordderived mesenchymal stem cells, when injected into CLP-induced sepsis mouse model, the exosomal miR-146a downregulated IRAK1, TRAF6, and IRF5, contributing to M2 polarization of macrophages and recovering of sepsis. This is an interesting disease protective aspect of this micro-RNA (Song et. al, 2017).

Significant overexpression of miR-146a in exosomes derived from vitreous humor as well as serum of uveal melanoma patients could serve as a potential biomarker for the disease (Ragusa et. al, 2015).

Micro RNA-181 group: The role of exosomal miR-181 has been observed both in disease development as well as in disease resistance. In a recent study, mi-RNA profiling of serum exosomes from hepatocellular carcinoma patients exhibited that, miR-181a can be considered as a potential non-invasive biomarker of the disease due to its stable expression ( $\mathrm{Li}$ et. al, 2015). There is evidence showing the role of exosomal miR-181 in disease resistance. For example, adipose-derived mesenchymal stem cells release exosomal miR-181-5p, which after being transferred to hepatic stellate cells induces autophagy by downregulating STAT3 and Bcl-2, and alleviated liver fibrosis (Qu et. al, 2017). Human liver stem-like cell-derived exosomes carry miR-181b, which suppressed the angiogenesis of tumor-derived endothelial cells, by downregulating the expressions of ITGB3, FGF1, EPHB4, and PLAU angiogenic genes (Lopatina et. al, 2019). Significant downregulation of miR-181b-5p and miR-181d was observed in exosomes derived from gastric cancer-associated-ascites than in those derived from liver cirrhosis-associated ascites. Moreover, the combination of miR-181b-5p and carcinoembryonic antigen showing significantly high specificity and sensitivity towards gastric cancer which was proved to be acting as the greatest diagnostic marker (Yun et al, 2019). Hypoxic colorectal cancer cell-derived exosomes contained miR-181a-5p, which was recovered in high-risk locally advanced rectal cancer acting as a marker of the disease (Bjørnetrø et. al, 2019). Mir-181a-5p was found to be upregulated in plasma exosomes of several other cancers also, hence used as a biomarker for detection of this disease (Samsonov et. al, 2016, Zhang et. al, 2019). An overexpression of exosomal hsa-miR-181a/b derived from human melanoma cells was found to suppress the TNFa secretion and T-cell receptor signaling and thus support the tumor progression (Vignard et. al, 2020). This reflects the disease resistance capability of this mi-RNA.

The high accumulation of miR-181b-5p in tumor-derived exosomes of adenocarcinoma patients could be assumed to serve as a potential biomarker for early detection of non-small cell lung cancer, adenocarcinoma (Jin et. al, 2017). Exosomes isolated from Adipose-derived stem cells (ADSCs) contained miR-181b-5p, which was further outstandingly increased by exposing the ADSCs to brain extracts of rat model with middle cerebral artery occlusion. These micro RNAs were transferred to oxygenglucose deprived brain microvascular endothelial cells (BMECs) resulting in endorsement of tube 
formation and migration of the BMECs through the downregulation of TRPM7, thus stimulating the angiogenesis of the BMECs (Yang et. al, 2018).

In the case of renal diseases, miR-181a was significantly decreased in the urinary exosomes of early as well as late chronic kidney disease patients by about 200 -fold, thus serving as a strong potential biomarker of the disease (Khurana et. al, 2017). Whereas, in another study, it was seen that the increased expression of miR-181 in serum exosomes due to acupuncture with low-frequency electrical stimulation in the hindlimb of mouse model seemed to increase renal blood flow, by downregulating the expression of angiotensinogen (Su et. al, 2018).

Micro RNA-1246: There are several reports available that studied the role of exosomal miR-1246 in breast cancer and assumed to be a factor that makes it a potential diagnostic marker for breast cancer (Hannafon et. al, 2016). A high expression of miR-1246 was observed in metastatic breast cancer cellderived exosomes, which after being transferred to non-malignant human mammary epithelial cells (HMLE) induces cell proliferation, migration and generates a chemotherapy-resistant capacity in them by downregulating CCNG2 (Li et. al, 2017). A significantly high expression of exosomal miR-1246 was observed in other cancer patients also such as ovarian cancer (Kanlikilicer et. al, 2018), prostate cancer (Bhagirath et. al, 2018), colorectal cancer (Eylem et. al, 2020), and gastric cancer (Shi et. al, 2020), etc. The level of miR-1246 was found to be significantly higher in serum exosomes of both early and advanced hepatocellular carcinoma patients, than in those of liver cirrhosis patients and normal control individuals, which help to detect hepatocellular carcinoma in both early and advanced stages, thus improving the possible treatments of the disease (Wang et. al, 2018). The upregulated miR-1246 in highly metastatic human oral squamous cell carcinoma (OSCC) cells, when get transferred into poorly metastatic OSCC cells, they increased the motility and invasion of the recipient cells by downregulating the expression of domain-containing 2D genes (Sakha et. al, 2016). This study indicates the association of exosomal miR-1246 with OSCC progression.

Mutant p53 acquire some gain-of-function due to which they act differently from wild-type p53, which acts as a tumor-suppressor. In a certain study, it has been found that colon cancer cells accommodating GOF mutp53, secreted exosomes with highly expressed miR-1246, which by being carried into neighbouring macrophages, resulted in their transformation into tumor-associated macrophages, by the increased expression of IL-10, VEGF, CCL2 and TGF- $\beta$ and the decreased expression of IL-8 and TNF-a. It has been also observed that these phenomena are associated with the poor survival of colon cancer patients (Cooks et. al, 2018). Interestingly, in a study, it was found that pulmonary artery smooth muscle cells (PASMC) secreted exosomes in which miR-1246 was downregulated due to platelet-derived growth factor (PDGF) stimulation applied on the PASMCs. These exosomes when get transferred into pulmonary artery endothelial cells (PAEC) due to the downregulated expression of miR-1246, an elevated migrating capacity of the PAECs was observed. This study explored the role of exosomal miR-1246 in maintaining vascular homeostasis and pathology (Heo et. al, 2020). 
Mir-1246 was elevated in exosomes secreted by Rhabdomyosarcoma cells, and they combined with another elevated micro RNA targeted pathways associated with tumorigenesis, particularly, Wnt and GnRH signaling pathways but also included angiogenesis signaling pathway and apoptotic signaling pathway. These exosomes were seemed to increase proliferation and angiogenesis in recipient fibroblast cells (Ghayad et. al, 2016). An interesting observation implied that miR-1246 released from lung cancer cells with ionizing radiation, both in exosomal and non-exosomal forms, but their expression was much less in exosomes than in extracellular space, that is their expression was higher in non-exosomal form and they resulted in proliferation and radio resistance of the recipient cells being in their non-exosomal form (Yuan et. al, 2016).

Increased expression of exosomal miR-1246 isolated from culture media of BEP2D cells with $2 \mathrm{~Gy}$ irradiation induces DNA damage in non-irradiated cells by the increased expression of 53BP1 foci, micronuclei, and comet tail (Mo et. al, 2018). Exosomal miR-1246 also serves as a potential biomarker for detecting acute myeloid leukemia (Hornick et. al, 2015).

Micro RNA-122: The most significant role of exosomal miR-122 was observed in the case of hepatic disease. The level of miR-122 was significantly reduced in exosomes isolated from hepatocellular carcinoma patients, compared to those isolated from chronic hepatitis B patients and liver cirrhosis patients, due to which it could serve as a potential serological marker for hepatocellular carcinoma (Liu et. al, 2015). In another study, the role of exosomal miR-122 was analyzed in hepatocellular carcinoma patients and it was found that the level of exosomal miR-122 was significantly decreased after transarterial chemoembolization (TACE) treatment, where before TACE the level of exosomal miR-122 was found to be significantly associated with aminotransferase and alanine aminotransferase levels. Therefore, these findings suggested that exosomal miR-122 could serve as a biomarker for hepatocellular carcinoma with liver cirrhosis after TACE treatment (Suehiro et. al, 2018). However, in another study, it was seen that transfecting adipose tissue-derived mesenchymal stem cells (AMSCs) with miR-122, results in secretion of exosomes carrying miR-122 which after transfer to hepatocellular carcinoma cells increases their sensitivity towards chemotherapy (Lou et. al, 2015). This study highlights the diseaseresistant capacity of exosomal miR-122 in the case of hepatocellular carcinoma. It was also shown that the level of exosomal miR-122 was significantly lower in hepatitis $C$ infected patients compared to healthy individuals except for $1 \mathrm{~b}$ genotype of hepatitis $C$ patients (Fan et. al. 2017). Acetaminophen (APAP) induced liver injury, elevates miR-122 and glutamate dehydrogenase level in 5-fold compared to the hepatic injury biomarker, alanine aminotransferase, and a part of this elevated miR-122 resides in the plasma exosomes released from the injured liver cells, suggesting that exosomal miR-122 can also act as a potential biomarker for drug-induced liver injury (Thulin et. al, 2016). In the case of thioacetamideinduced injury, the level of exosomal miR-122 decreased than the control after $12 \mathrm{~h}$ of administration in the injured rat model and then increased at $24 \mathrm{~h}$ (Motawi et. al, 2018). All implied that exosomal miR-122 is a promising biomarker for acute liver injury. The level of exosomal miR-122 derived from hepatocytes of the mouse model was found to be significantly increased after alcohol consumption, the same was observed in the case of human hepatocytes. The exosomal miR-122 being transferred into monocytes, 
decrease the level of HO-1, resulting in the increased expression of IL- $\beta$ and increase of inflammation favourable activities of the monocytes (Momen-Heravi et. al, 2015). The level of hsa-122-5p in serum exosomes collected from patients with chronic atrophic gastritis was significantly higher compared to chronic non-atrophic gastritis, which indicated that exosomal hsa-miR-122-5p was also a potential biomarker for chronic atrophic gastritis analysis (Liu et. al, 2019). It was also identified to be a promising biomarker for colorectal cancer, as the level of exosomal miR-122 significantly increased in the case of colorectal cancer patients than in healthy patients (Sun et. al, 2020). There are some significant roles of exosomal miR-122 in breast cancer disease. Breast cancer cells were found to secrete exosomes carrying elevated level of miR-122, which is transferred into lung fibroblasts, brain astrocytes, and neurons put down the level of GLUT1 and PKM2, also putting down the glucose consumption by the cells and accelerated their metastasis (Fong et. al, 2015). It was found that miR-122-5p was one of those mi-RNAs which was significantly elevated in plasma exosomes of breast cancer patients than in normal individuals, offering it to be a potential biomarker for breast cancer (Li et. al, 2019). Even liver cells carried exosomal miR-122-5p in a huge amount that could suppress syndecan-1, a heparan sulfate proteoglycan, associated with several malignant carcinomas, that further lead to the increased motility of breast cancer cells (Uen et. al, 2018).

Interestingly, exosomal miR-122-5p can also be used for the treatment of osteonecrosis of the femoral head (ONFH) by generating osteoblast cells, as observed in rabbit models (Liao et. al, 2019). This is strong evidence indicating the defensive role of exosomal miR-122 in bone-related hemorrhages. The hsamiR-122 was one of those mi-RNAs which were present in a huge amount in exosomes isolated from melanoma tumor cells and associated with the immune evasion of tumor growth (Vignard et. al, 2020). Additionally, the incorporation of miR-122-5p into melanoma cells is influenced by lysophosphatidic acid receptor-3 (LPAR3) and the partial involvement of PGC-1a (Byrnes et. al, 2019). Plasma exosomal rno-miR-122-5p was downregulated in rats with the transient ischemic attack, than in control rats, thus acting as a potential biomarker for the analysis of this disease ( $\mathrm{Li}$ et. al, 2018).

Micro RNA-155: Breast cancer is of utmost importance because of being one of the prime causes of fatality in women and the exosomal miR-155 family offers some incredibly significant role in this disease. No significant difference in the level of miR-155 existed between exosomes of breast cancer patients than that of healthy individuals though the concentration of exosomes was high in the case of breast cancer patients (Gonzalez-Villasana et. al, 2019). It was seen that chemo-resistant breast cancer cell-secreted exosomal miR-155 when transferred into chemo-sensitive breast cancer cells it makes them chemo resistant (Santos e.t al, 2018). Moreover, miR-155 downregulates PPARy expression in the adipocytes and causes cancer-associated cachexia which induces cell metastasis in breast cancer (Wu et. al, 2019). Additionally, it was reported that the transfer of exosomal miR-155 from high metastatic triple-negative breast cancer cells to low metastatic breast cancer cells, can downregulate the expression of tumor suppressor genes PTEN and DUSP14 and induce the metastatic behavior of the recipient cells (Kia et. al, 2018). M2 macrophage-derived exosomes exhibited significantly higher expression of miR-155$5 p$, which transported them into colorectal cancer cells, where this exosomal miR down regulatesBRG1, 
the regulatory factor of colorectal cancer cell metastasis (Lan et. al, 2019). Additionally, exosomal miR155-5p derived from paclitaxel-resistant gastric cancer cells when transferred to the paclitaxel sensitive gastric cancer induces epithelial-mesenchymal transition and drug-resistant capacity in those recipient cells through downregulation of GATA3 and TP53INP1 expression (Wang et. al, 2019). The level of miR155 in acute myeloid leukemia (AML) exosomes were found to be increased with disease development and can be considered as a minimally invasive biomarker for early detection of AML (Hornick et. al, 2015). A similar finding was observed in the case of chronic lymphocytic leukemia (CLL) (Yeh et. al, 2015). Therefore, these studies implied that exosomal miR-155 is a strong candidate for tracing the disease profile of different types of cancers and leukemia. It is also reported that miR-155 has a role in the development of type 1 diabetes. T-lymphocytes of both human and non-obese diabetic mice secrete exosomes that carried miR-155. On being transferred to $\beta$ cells these exosomal miRNAs result in the induction of $\beta$ cell apoptosis, also upregulating the expression of CCL2, CCL7, and CXCL10 (Guay et. al, 2019). In another study, it was found that cytokine-treated islet cell-derived exosomes, collected from nondiabetic cadaveric donors carried highly upregulated hsa-miR-155-5p. The treatment of islets by the cytokines such as IL-1 $\beta$ and IFN- $\gamma$ was useful in creating a mimic of the pro-inflammatory ambiance of type 1 diabetes and thus the differential expression of exosomal miR-155-5p was assumed to serve as a marker for type 1 diabetes (Krishnan et. al, 2019).

Interestingly, the disease resisting role of this exosomal miR-155 was also observed in the inhibition of Enterovirus A71 (EV-A71) infection by suppression of VP1 protein and virus genomic RNA (Wu et. al, 2019). It was observed that the serum exosomes isolated from the rheumatic heart disease (RHD) rat model carried significantly upregulated miR-155-5p which downregulated the expression of S1PR1 and SOCS1 and activated STAT3 phosphorylation along with IL-6 expression leading to the valvular damage. But, inhibiting the expression of exosomal miR-155-5p, could mitigate the damages in RHD cases (Chen et. al, 2020). The level of exosomal miR-155 was found to be significantly upregulated in rheumatoid arthritis (RA) patients infected with hepatitis $\mathrm{C}$ virus $(\mathrm{HCV})$ than in RA patients without $\mathrm{HCV}$ infections, but this expression of miR-155 suppressed HCV replication which could relapse upon rituximab therapy (Liao et. al, 2018). This study indicated the disease recovery role of exosomal miR-155.

Coming back to the disease developing aspects, it was seen that melanoma derived exosomal miR-155 downregulates cytokine signaling 1 (SOCS1) expression, leading to the activation of JAK2/STAT3 signaling pathway and the induction of vascular endothelial growth factor A, fibroblast growth factor 2 , and matrix metalloproteinase 9 expressions, thus generating angiogenesis in the normal fibroblast cells and transforming them into cancer-associated fibroblasts (Zhou et. al, 2018). Co-culturing melanoma cells with neuroblastoma cells lead to the increased expression of miR-155 in human monocytes and it is believed to be caused by neuroblastoma-derived exosomes carrying upregulated miR-155. It was also observed that, in a co-culture of monocytes and neuroblastoma, human monocytes secreted exosomal miR-155, causes downregulation of TERF1 expression and increases telomerase activity in the recipient neuroblastoma cells, and makes them drug-resistant. This study was an example of how exosomal miR155 acted as a mediator of cross-talk between human monocytes and neuroblastoma (Challagundla et. 
al, 2015). The transfer of exosomal miR-155 from Epstein-Barr virus-infected Burkitt's lymphoma cells to the retinal pigment epithelial (RPE) cells resulted in an elevated level of miR-155 in the RPE cells also leading to the induction of VEGF-A expression, thus bringing about angiogenic properties in them (Yoon et. al, 2016). The exosomal level of miR-155 was found to be elevated in the case of pregnant women with preeclampsia, than in women with normal pregnancy. Moreover, it was observed that the transfer of this miR-155 from placenta associated serum of PE patients to the primary human umbilical vein endothelial cells via exosomes, resulted in reduced nitric oxide (NO) production and eNOS expression in the recipient cells, thus inducing a PE favorable environment in the endothelial cells (Shen et. al, 2018).

Micro RNA-150: There are several experimental pieces of evidence suggesting the differential role of miR150 in leukemia. The plasma exosomes of chronic lymphocytic leukemia cells were found to deliver miR150 to recipient bone marrow mesenchymal stromal cells, which would develop inflammatory characteristics and cancer-associated fibroblast-like phenotype in these cells (Paggetti et. al, 2015). The differential expression of miRNA-150 in serum exosomes of mice with acute myeloid leukemia (AML)can act as a potential biomarker for detecting the disease (Hornick et. al, 2015). Moreover, there is also a significant correlation between $B$ cell receptor signaling pathway activation and increased secretion of exosomal miR-150 in Chronic Lymphocytic Leukaemia (Yeh et. al, 2015).

It is already reported that exosomal miR-150 could serve as a biomarker for different renal diseases, bladder cancer, triple-negative breast cancer patients, non-small cell lung cancer patients than in those of healthy individuals which were useful in the detection and diagnosis of these cancers (Xie et al., 2017; Armstrong et al. 2015; Wu et. al, 2020; Roman-Canal et. al, 2019). Due to their overexpression in urinary exosomes of patients with type 2 diabetic kidney disease and their possible association in the regulation of mTOR, p53, and AMPK pathways, exosomal miR-150 is considered as a potential biomarker of type 2 diabetic nephropathy (Xie et. al, 2017). In another article, it was revealed that mesenchymal stem cellderived exosomal miR-150-5p served as a therapeutic for decreasing the severe effect of arthritis in rheumatoid arthritis patients (Chen et. al, 2018).

From the overall discussion, we get to know that the differential expressions of various exosomal micro RNAs may serve as either a disease mediator or a biomarker or a therapeutic. The diseases mostly included different types of carcinoma, though there are also some unusual as well as well-known diseases that seemed to be affected by the different types of miRNA cargo of the exosomes. The search of such roles of these exosomal micro RNAs in disease development or disease defence is still going on which will provide new openings for the treatment procedures of the diseases.

\section{Conclusion}

Exosome has been established as a potential carrier of different types of cargos, specifically miRNAs. The emerging field of exosome-related research works is offering more consequences to use them as a carrier of therapeutic cargos. The review enlightens the aspects of using exosome as a communicating vehicle to treat a broad number of diseases, as well as the negative impact of the exosome-mediated 
delivery of miRNA on a cell, leading to the upsurge of disease development provides new challenges for the researchers to deal with in the future works.

\section{Declarations}

\section{Acknowledgement}

We greatly acknowledge Rashtriya Uchchatar Shiksha Abhiyan (RUSA) 2.0 (Reference No. R11/400/2019, Date:19/4/19) , Government of India for funding this research.

\section{Affiliations}

Department of Life Science and Biotechnology, Jadavpur University, Kolkata 700032, West Bengal, India

Rachayeeta Ray \& Parimal Karmakar

Department of Microbiology, Maulana Azad College, Kolkata 700013, West Bengal, India

Debalina Bhattacharya

\section{Corresponding author}

Correspondence to Parimal Karmakar.

\section{Conflict of interest}

We have no conflict of interest.

\section{Ethical approval}

This review article does not contain any studies with human participants or animals performed by any of the authors.

\section{Consent for publication}

All the authors approved the publication.

\section{References}

1. Amuran GG, Tinay I, Filinte D, Ilgin C, Eyüboğlu IP, Akkiprik M (2020) Urinary microRNA expressions and protein concentrations may differentiate bladder cancer patients from healthy controls. Int Urol Nephrol 52(3):461-468. https://doi.org/10.1007/s11255-019-02328-6

2. Armstrong DA, Green BB, Seigne JD, Schned AR, Marsit CJ (2015) MicroRNA molecular profiling from matched tumor and bio-fluids in bladder cancer. Molecular Cancer 14:194-199. 
https://doi.org/10.1186/s12943-015-0466-2

3. Barile L, Vassalli G (2017) Exosomes: Therapy delivery tools and biomarkers of diseases. Pharmacol Ther 174:63-78. https://doi.org/10.1016/j.pharmthera.2017.02.020

4. Beg F, Wang R, Saeed Z, Devaraj S, Masoor K, Nakshatri H (2017) Inflammation-associated microRNA changes in circulating exosomes of heart failure patients. BMC Research Notes 10:751756. https://doi.org/10.1186/s13104-017-3090-y

5. Beltrami C, Besnier M, Shantikumar S, Shearn AIU, Rajakaruna C, Laftah A, Sessa F, Spinetti G, Petretto E, Angelini GD, Emanueli C (2017) Human Pericardial Fluid Contains Exosomes Enriched with Cardiovascular-Expressed MicroRNAs and Promotes Therapeutic Angiogenesis. Mol Ther 25(3):679-693. https://doi.org/10.1016/j.ymthe.2016.12.022

6. Bhagirath D, Yang TL, Bucay N, Sekhon K, Majid S, Shahryari V, Dahiya R, Tanaka Y, Saini S (2018) MicroRNA-1246 is an exosomal biomarker for aggressive prostate cancer. Can Res 78(7):18331844. https://doi.org/10.1158/0008-5472.can-17-2069

7. Bhome R, Goh RW, Bullock MD, Pillar N, Thirdborough SM, Mellone M, Mirnezami R, Galea D, Veselkov K, Gu Q, Underwood TJ, Primrose JN, Wever OD, Shomron N, Sayan AE, Mirnezami AH (2017) Exosomal microRNAs derived from colorectal cancer-associated fibroblasts: role in driving cancer progression. Aging 9(12):2666-2694. https://doi.org/10.18632/aging.101355

8. Bjørnetrø T, Redalena KR, Meltzera S, Thusyanthana NS, Samiappand R, Jegerschöldd C, Handelanda KR, Ree AH (2019) An experimental strategy unveiling exosomal microRNAs 486-5p, $181 a-5 p$ and $30 d-5 p$ from hypoxic tumour cells as circulating indicators of high-risk rectal cancer. Journal Of Extracellular Vesicles 8:1567219. https://doi.org/10.1080/20013078.2019.1567219

9. Byrnes CC, Jia W, Alshamrani AA, Kuppa SS, Murph MM (2019) miR-122-5p Expression and Secretion in Melanoma Cells Is Amplified by the LPAR3 SH3-Binding Domain to Regulate Wnt1. Mol Cancer Res 17(1):299-309. https://doi.org/10.1158/1541-7786.mcr-18-0460

10. Cai J, Qiao B, Gao N, Lin N, He W (2019) OSCC-derived exosomes promote M2-subtype macrophage polarization mediated by exosome-enclosed miR-29a-3p. American Physiological Society 316:731740. https://doi.org/10.1152/ajpcell.00366.2018

11. Cao L, Yang X, Chen Y, Zhang D, Jiang X, Xue P (2019) Exosomal miR-21 regulates the TETs/PTENp1/PTEN pathway to promote hepatocellular carcinoma growth. Molecular Cancer 18:148. https://doi.org/10.1186/s12943-019-1075-2

12. Cao XY, Lu JM, Zhao ZQ, Li MC, Lu T, An XS, Xue LJ (2017) MicroRNA biomarkers of Parkinson's disease in serum exosome-like microvesicles. Neurosci Lett 644:94-99. https://doi.org/10.1016/j.neulet.2017.02.045

13. Challagundla KB, Wise PM, Neviani P, Chava H, Murtadha M, Xu T, Kennedy R, Ivan C, Zhang X, Vannini I, Fanini F, Amadori D, Calin GA, Hadjidaniel M, Shimada H, Jong A, Seeger RC, Asgharzadeh S, Goldkorn A, Fabbri M (2015) Exosome-Mediated Transfer of microRNAs Within the Tumor Microenvironment and Neuroblastoma Resistance to Chemotherapy. J Natl Cancer Inst 107(7):1-13. https://doi.org/10.1093/jnci/djv135 
14. Chang TY, Tsai WC, Huang TS, Su SH, Chang CY, Ma HY, Wu CH, Yang C-Y, Lin C-H, Huang P-H, Cheng C-C, Cheng S-M, Wang H-W (2017) Dysregulation of endothelial colony-forming cell function by a negative feedback loop of circulating miR-146a and $-146 \mathrm{~b}$ in cardiovascular disease patients. Plos One 12(7):1-25. https://doi.org/10.1371/journal.pone.0181562

15. Chaturvedi P, Kalani A, Medina I, Familtseva A, Tyagi SC (2015) Cardiosome mediated regulation of MMP9 in diabetic heart: role of mir29b and mir455 in exercise. J Cell Mol Med 19(9):2153-2161. https://doi.org/10.1111/jcmm.12589

16. Chen A, Wen J, Lu C, Lin B, Xian S, Huang F, Wu Y, Zeng Z (2020) Inhibition of miR1555p attenuates the valvular damage induced by rheumatic heart disease. International Journal of Molecular medicine 45:429-440. https://doi.org/10.3892/ijmm.2019.4420

17. Chen Z, Wang H, Xia Y, Yan F, Lu Y (2018) Therapeutic Potential of Mesenchymal Cell-Derived miRNA-150-5p-Expressing Exosomes in Rheumatoid Arthritis Mediated by the Modulation of MMP14 and VEGF. J Immunol (8):2472-2482. https://doi.org/10.4049/jimmunol.1800304

18. Cooks T, Pateras IS, Jenkins LM, Patel KM, Robles Al, Morris J, Forshew T, Appella E, Gorgoulis VG, Harris CC (2018) Mutant p53 cancers reprogram macrophages to tumor supporting macrophages via exosomal miR-1246. Nat Commun 9:771. https://doi.org/10.1038/s41467-018-03224-w

19. Dong C, Zhou Q, Fu T, Zhao R, Yang J, Kong X, Zhang Z, Sun C, Bao Y, Ge X, Zhang Z, Lu Z, Li J, Zheng W, Gu Z, Ji J (2019) Circulating Exosomes Derived-miR-146a from Systemic Lupus Erythematosus Patients Regulates Senescence of Mesenchymal Stem Cells. Biomed Res Int 1-10. https://doi.org/10.1155/2019/6071308

20. Donnarumma E, Fiore D, Nappa M, Roscigno G, Adamo A, laboni M, Russo V, Affinito A, Puoti I, Quintavalle C, Rienzo A, Piscuoglio S, Thomas R, Condorelli G (2017) Cancer-associated fibroblasts release exosomal microRNAs that dictate an aggressive phenotype in breast cancer. Oncotarget 8(12):19592-19608. https://doi.org/10.18632/oncotarget.14752

21. Duan L, Xu L, Xu X, Qin Z, Zhou X, Xiao Y, Liang Y, Xia J (2021) Exosome-mediated delivery of gene vectors for gene therapy. Nanoscale 13:1387-1397. https://doi.org/10.1039/d0nr07622h

22. Eylem CC, Yilmaz M, Derkus B, Nemutlu E, Camci CB, Yilmaz E, Turkoglu MA, Aytac B, Ozyurt N, Emregul E (2020) Untargeted Multi-Omic Analysis of Colorectal Cancer-Specific Exosomes Reveals Joint 2 Pathways of Colorectal Cancer in both Clinical Samples and Cell Culture. Cancer Lett 469:186-194. https://doi.org/10.1016/j.canlet.2019.10.038

23. Fan B, Li C, Szalad A, Wang L, Pan W, Zhang R, Chopp M, Zhang ZG, Liu XS (2020) Mesenchymal stromal cell-derived exosomes ameliorate peripheral neuropathy in a mouse model of diabetes. Diabetologia 63:431-443. https://doi.org/10.1007/s00125-019-05043-0

24. Fan Z, Zhang Q, Chen H, He P, Li Y, Si M, Jiao X (2017) Circulating microRNAs as a biomarker to predict therapy efficacy in hepatitis $C$ patients with different genotypes. Microb Pathog 112:320326. https://doi.org/10.1016/j.micpath.2017.10.003

25. Fong MY, Zhou W, Liu L, Alontaga AY, Chandra M, Ashby J, Chow A, O'Connor STF, Li S, Chin AR, Somlo G, Palomares M, Li Z, Tremblay JR, Tsuyada A, Sun G, Reid MA, Wu X, Swiderski P, Ren X, Shi 
Y, Kong M, Zhong W, Chen Y, Wang SE (2015) Breast cancer-secreted miR-122 reprograms glucose metabolism in pre-metastatic niche to promote metastasis. Nat Cell Biol 17(2):183-194. https://doi.org/10.1038/ncb3094

26. Fu Y, Zhang L, Zhang F, Tang T, Zhou Q, Feng C, Jin Y, Wu Z (2017) Exosome-mediated miR-146a transfer suppresses type I interferon response and facilitates EV71 infection. Plos Pathogens 13(9):1-31. https://doi.org/10.1371/journal.ppat.1006611

27. Ghayad SE, Rammal G, Ghamloush F, Basma H, Nasr R, Diab-Assaf M, Chelala C, Saab R (2016) Exosomes derived from embryonal and alveolar rhabdomyosarcoma carry differential miRNA cargo and promote invasion of recipient fibroblast. Sci Rep 6:37088-37015. https://doi.org/10.1038/srep37088

28. Gonzalez-Villasana V, Rashed MH, Gonzalez-Cantú Y, Bayraktar R, Menchaca-Arredondo JL, VazquezGuillen JM, Rodriguez-Padilla C, Lopez-Berestein G, Resendez-Perez D (2019) Presence of Circulating miR-145, miR-155, and miR-382 in Exosomes Isolated from Serum of Breast Cancer Patients and Healthy Donors. Dis Markers 6852917:1-9. https://doi.org/10.1155/2019/6852917

29. Goto T, Fujiya M, Konishi H, Sasajima J, Fujibayashi S, Hayashi A, Utsumi T, Sato H, Iwama T, ljiri M, Sakatani A, Tanaka K, Nomura Y, Ueno N, Kashima S, Moriichi K, Mizukami Y, Kohgo Y, Okumura T (2018) An elevated expression of serum exosomal microRNA-191, $-21,-451$ a of pancreatic neoplasm is considered to be efficient diagnostic marker. BMC Cancer 18:116. https://doi.org/10.1186/s12885-018-4006-5

30. Guay C, Kruit JK, Rome S, Menoud V, Mulder NL, Jurdzinski A, Mancarella F, Sebastiani G, Donda A, Gonzalez BJ, Jandus C, Bouzakri K, Pinget M, Boitard C, Romero P, Dotta F, Regazzi R (2019) Lymphocyte-Derived Exosomal MicroRNAs Promote Pancreatic $\beta$ Cell Death and May Contribute to Type 1 Diabetes Development. Cell Metab 29:348-361. https://doi.org/10.1016/j.cmet.2018.09.011

31. Gui YX, Liu H, Zhang L, Lv W, Hu XY (2015) Altered microRNA profiles in cerebrospinal fluid exosome in Parkinson disease and Alzheimer disease. Oncotarget 6(35):37043-37053. https://doi.org/10.18632/oncotarget.6158

32. Guo X, Qiu W, Wang J, Liu Q, Qian M, Wang S, Zhang Z, Gao X, Chen Z, Guo Q, Xu J, Xue H, Li G (2019) Glioma exosomes mediate the expansion and function of myeloid-derived suppressor cells through microRNA-29a/Hbp1 and microRNA-92a/Prkar1a pathways. Int J Cancer 144:3111-3126. https://doi.org/10.1002/ijc.32052

33. Gysler SM, Mulla MJ, Guerra M, Brosens JJ, Salmon JE, Chamley LW, Abrahams VM (2016) Antiphospholipid antibody-induced miR-146a-3p drives trophoblast interleukin-8 secretion through activation of Toll-like receptor 8. Mol Hum Reprod 22(7):465-474.

https://doi.org/10.1093/molehr/gaw027

34. Hannafon BN, Trigoso YD, Calloway CL, Zhao YD, Lum DH, Welm AL, Zhao ZJ, Blick KE, Dooley WC, Ding WQ (2016) Plasma exosome microRNAs are indicative of breast cancer. Breast Cancer Res 18(90):1-14. https://doi.org/10.1186/s13058-016-0753-x 
35. Haug BH, Hald ØH, Utnes P, Roth SA, Løkke C, Flægstad T, Einvik C (2015) Exosome-like Extracellular Vesicles from MYCN-amplified Neuroblastoma Cells Contain Oncogenic miRNAs. Anticancer Research 35:2521-30. PMID: 25964525

36. Heo J, Yang HC, Rhee WJ, Kang H (2020) Vascular Smooth Muscle Cell-Derived Exosomal MicroRNAs Regulate Endothelial Cell Migration Under PDGF Stimulation. Cells 9(3):639-616. https://doi.org/10.3390/cells9030639

37. Honegger A, Schilling D, Bastian S, Sponagel J, Kuryshev V, Sültmann H, Scheffner M, Hoppe-Seyler K, Hoppe-Seyler F (2015) Dependence of Intracellular and Exosomal microRNAs on Viral E6/E7 Oncogene Expression in HPV-positive Tumor Cell. PLoS Pathog 11(3):1-33. https://doi.org/10.1371/journal.ppat.1004712

38. Hornick NI, Huan J, Doron B, Goloviznina NA, Lapidus J, Chang BH, Kurre P (2015) Serum Exosome MicroRNA as a Minimally-Invasive Early Biomarker of AML. Sci Rep 5:11295-11212. https://doi.org/10.1038/srep11295

39. Hu W, Xu B, Zhang J, Kou C, Liu J, Wang Q, Zhang R (2020) Exosomal miR-146a-5p from Treponema pallidum-stimulated macrophages reduces endothelial cells permeability and monocyte transendothelial migration by targeting JAM-C. Exp Cell Res 388:111823. https://doi.org/10.1016/j.yexcr.2020.111823

40. Jerez S, Araya H, Hevia D, Irarrázaval CE, Thaler R, Wijnen AJV, Galindo M (2019) Extracellular vesicles from osteosarcoma cell lines contain miRNAs associated with cell adhesion and apoptosis. Gene 710:246-257. https://doi.org/10.1016/j.gene.2019.06.005

41. Jin X, Chen Y, Chen H, Fei S, Chen D, Cai X, Liu L, Lin B, Su H, Zhao L, Su M, Pan H, Shen L, Xie D, Xie C (2017) Evaluation of Tumor-Derived Exosomal miRNA as Potential Diagnostic Biomarkers for Early-Stage Non-Small Cell Lung Cancer Using Next-Generation Sequencing, American Association for Cancer Research. 23(17):5311-19. https://doi.org/10.1158/1078-0432.ccr-17-0577

42. Jurj A, Pop L, Petrushev B, Pasca S, Dima D, Frinc I, Deak D, Desmirean M, Trifa A, Fetica B, Gafencu G, Selicean S, Moisoiu V, Micu W-T, Berce C, Sacu A, Moldovan A, Colita A, Bumbea H, Tanase A, Dascalescu A, Zdrenghea M, Stiufiuc R, Leopold N, Tetean R, Burzo E, Tomuleasa C, Berindan-Neagoe I (2018) Exosome-carried microRNA-based signature as a cellular trigger for the evolution of chronic lymphocytic leukemia into Richter syndrome. Crit Rev Clin Lab Sci 55(7):501-515. https://doi.org/10.1080/10408363.2018.1499707

43. Kalani A, Chaturvedi P, Maldonado C, Bauer P, Joshua IG, Tyagi SC, Tyagi N (2017) Dementia-like pathology in type-2 diabetes: A novel microRNA mechanism. Mol Cell Neurosci 80:58-65. https://doi.org/10.1016/j.mcn.2017.02.005

44. Kanlikilicer P, Bayraktar R, Denizli M, Rashed MH, Ivan C, Aslan B, Mitra R, Karagoz K, Bayraktar E, Zhang X, Rodriguez-Aguayo C, El-Arabey AA, Kahraman N, Baydogan S, Ozkayar O, Gatza ML, Ozpolat B, Calin GA, Sood AK, Lopez-Berestein G (2018) Exosomal miRNA confers chemo resistance via targeting Cav1/p-gp/M2-type macrophage axis in ovarian cancer. EBiomedicine 38:100-112. https://doi.org/10.1016/j.ebiom.2018.11.004 
45. Khurana R, Ranches G, Schafferer S, Lukasser M, Rudnicki M, Mayer G, Hüttenhofer A (2017) Identification of urinary exosomal noncoding RNAs as novel biomarkers in chronic kidney disease. RNA 23:142-152. https://doi.org/10.1261/rna.058834.116

46. Kia V, Paryan M, Mortazavi Y, Biglari A, Mohammadi-Yeganeh S (2018) Evaluation of exosomal miR9 and miR-155 targeting PTEN and DUSP14 in highly metastatic breast cancer and their effect on low metastatic cells. J Cell Biochem 120:1-11. https://doi.org/10.1002/jcb.27850

47. Kim G, Kim M, Lee Y, Byun JW, Hwang DW, Lee M (2020) Systemic delivery of microRNA-21 antisense oligonucleotides to the brain using T7-peptide decorated exosomes. J Controlled Release 317:273281. https://doi.org/10.1016/j.jconrel.2019.11.009

48. Kimura K, Hohjoh H, Fukuoka M, Sato W, Oki S, Tomi C, Yamaguchi H, Kondo T, Takahashi R, Yamamura T (2018) Circulating exosomes suppress the induction of regulatory $\mathrm{T}$ cells via let-7i in multiple sclerosis. Nature Commununications 9:17-14. https://doi.org/10.1038/s41467-017-024062

49. Krishnan P, Syed F, Kang NJ, Mirmira RG, Evans-Molina C (2019) Profiling of RNAs from Human IsletDerived Exosomes in a Model of Type 1 Diabetes. International Journal of Molecular Science 20:5903-5916. https://doi.org/10.3390/ijms20235903

50. Lan J, Sun L, Xu F, Liu L, Hu F, Song D, Hou Z, Wu W, Luo X, Wang J, Yuan X, Hu J, Wang G (2019) M2 Macrophage-Derived Exosomes Promote Cell Migration and Invasion in Colon Cancer. Can Res 79(1):146-158. https://doi.org/10.1158/0008-5472.can-18-0014

51. Li DB, Liu JL, Wang W, Luo XM, Zhou X, Li JP, Cao XL, Long XH, Chen JG, Qin C (2018) Plasma Exosomal miRNA-122-5p and miR-300-3p as Potential Markers for Transient Ischaemic Attack in Rats. Frontiers of in Aging Neuroscience 10:1-10. https://doi.org/10.3389/fnagi.2018.00024

52. Li XJ, Ren ZJ, Tang JH, Yu Q (2017) Exosomal MicroRNA MiR-1246 Promotes Cell Proliferation, Invasion and Drug Resistance by Targeting CCNG2 in Breast Cancer. Cell Physiol Biochem 44:17411748. https://doi.org/10.1159/000485780

53. Li M, Zou X, Xia T, Wang T, Liu P, Zhou X, Wang X, Zhu W (2017) A five-miRNA panel in plasma was identified for breast cancer diagnosis. Cancer Med 8:7006-7017. https://doi.org/10.1002/cam4.2572

54. Li P, Kaslan M, Lee SH, Yao J, Gao Z (2017) Progress in Exosome Isolation Techniques. Theranostics 7(3):789-804. https://doi.org/10.7150/thno.18133

55. Li Q, Li B, Li Q, Wei S, He Z, Huang X, Wang L, Xia Y, Xu Z, Li Z, Wang W, Yang L, Zhang D, Xu Z (2018) Exosomal miR-21-5p derived from gastric cancer promotes peritoneal metastasis via mesothelial-tomesenchymal transition. Cell Death Dis 9:854-817. https://doi.org/10.1038/s41419-018-0928-8

56. Li Y, Zhang L, Liu F, Xiang G, Jiang D, Pu X (2015) Identification of Endogenous Controls for Analyzing Serum Exosomal miRNA in Patients with Hepatitis B or Hepatocellular Carcinoma. Disease Markers 1-12. https://doi.org/10.1155/2015/893594

57. Liang YC, Wu YP, Li XD, Chen SH, Ye XJ, Xue XY, Xu N (2019) TNF-a-induced exosomal miR-146a mediates mesenchymal stem cell-dependent suppression of urethral stricture. J Cell Physiol 
234:23243-23255. https://doi.org/10.1002/jcp.28891

58. Liao TL, Hsie SL, Chen YM, Chen HH, Liu HJ, Lee HC, Chen DY (2018) Rituximab may cause increased hepatitis $\mathrm{C}$ virus viremia in rheumatoid arthritis patients through declining exosomal microRNA-155. Arthritis Rheumatology 70:1209-1219. https://doi.org/10.1002/art.40495

59. Liao W, Ning Y, Xu HJ, Zou WZ, Hu J, Liu XZ, Yang Y, Li Z-H (2019) BMSCs-derived Exosomes Carrying MicroRNA-122-5p Promote Progression of Osteoblasts in Osteonecrosis of the Femoral Head. Clin Sci 133:1955-1975. https://doi.org/10.1042/cs20181064

60. Lin H, Zhang Z (2019) Diagnostic value of a microRNA signature panel in exosomes for patients with hepatocellular carcinoma. International Journal of Clinical Experimental Pathology 12(4):14781487. http://www.ncbi.nlm.nih.gov/pmc/articles/pmc6947065/

61. Liu H, Li P, Yang W, Mi H, Pan J, Huang Y, Hou Z, Hou Q, Luo Q, Liu F (2019) Identification of noninvasive biomarkers for chronic atrophic gastritis from serum exosomal microRNAs. BMC Cancer 19:129-110. https://doi.org/10.1186/s12885-019-5328-7

62. Liu T, Chen G, Sun D, Lei M, Li Y, Zhou C, Li X, Xue W, Wang H, Liu C, Xu J (2017) Exosomes containing miR-21 transfer the characteristic of cisplatin resistance by targeting PTEN and PDCD4 in oral squamous cell carcinoma. Acta Biochim Biophys Sin 49(9):808-816. https://doi.org/10.1093/abbs/gmx078

63. Liu W, Ren L, Wang X, Wang T, Zhang N, Gao Y, Luo H, NavarroAlvarez N, Tang L (2015) Combination of exosomes and circulating microRNAs may serve as a promising tumor marker complementary to alpha-fetoprotein for early-stage hepatocellular carcinoma diagnosis in rats. J Cancer Res Clin Oncol 141:1767-1778. https://doi.org/10.1007/s00432-015-1943-0

64. Liu Y, Zhang Y, Liu P, Bai H, Li X, Xiao J, Yuan Q, Geng S, Yin H, Zhang H, Wang Z, Li J, Wang S, Wang $Y$ (2019) MicroRNA-128 knockout inhibits the development of Alzheimer's disease by targeting PPARy in mouse models. Eur J Pharmacol 843:134-144. https://doi.org/10.1016/j.ejphar.2018.11.004

65. Lopatina T, Grange C, Fonsato V, Tapparo M, Brossa A, Fallo S, Pitino A, Herrera-Sanchez MB, Kholia S, Camussi G, Bussolati B (2019) Extracellular vesicles from human liver stem cells inhibit tumor angiogenesis. Int J Cancer 144:322-333. https://doi.org/10.1002/ijc.31796

66. Lou G, Song X, Yang F, Wu S, Wang J, Chen Z, Liu Y (2015) Exosomes derived from miR-122-modified adipose tissue-derived MSCs increase chemosensitivity of hepatocellular carcinoma. J Hematol Oncol 8:122-111. https://doi.org/10.1186/s13045-015-0220-7

67. Luther KM, Haar L, McGuinness M, Wang Y, Lynch T, Phan A, Song Y, Shen Z, Gardner G, Kuffel G, Ren $X$, Zilliox MJ, Jones WK (2018) Exosomal miR-21a-5p mediates cardioprotection by mesenchymal stem cells. J Mol Cell Cardiol 119:125-137. https://doi.org/10.1016/j.yjmcc.2018.04.012

68. Lv C, Ding W, Wang Y, Zhao Z, Li J, Chen Y, Lv J (2018) A PEG-based method for the isolation of urinary exosomes and its application in renal fbrosis diagnostics using cargo miR-29c and miR-21 analysis. Int Urol Nephrol 50:973-982. https://doi.org/10.1007/s11255-017-1779-4 
69. Mizuno K, Mataki H, Arai T, Okato A, Kamikawaji K, Kumamoto T, Hiraki T, Hatanaka K, Inoue H, Seki $\mathrm{N}$ (2017) The microRNA expression signature of small cell lung cancer: tumor suppressors of miR27a-5p and miR-34b-3p and their targeted oncogene. J Hum Genet 1-8. https://doi.org/10.1038/jhg.2017.27

70. Mo L-J, Song M, Huang Q-H, Guan H, Liu X-D, Xie D-F, Huang B, Huang R-X, Zhou P-K (2018) Exosome-packaged miR-1246 contributes to bystander DNA damage by targeting LIG4. Br J Cancer 119:492-502. https://doi.org/10.1038/s41416-018-0192-9

71. Momen-Heravi F, Bala S, Kodys K, Szabo G (2015) Exosomes derived from alcoholtreated hepatocytes horizontally transfer liver specific miRNA-122 and sensitize monocytes to LPS. Sci Rep 5:09991-09916. https://doi.org/10.1038/srep09991

72. Motawi TK, Mohamed MR, Shahin NN, Ali MAM, Azzam MA (2018) Time-course expression profile and diagnostic potential of a miRNA panel in exosomes and total serum in acute liver injury. The International Journal of Biochemistry Cell Biology 100:11-21. https://doi.org/10.1016/j.biocel.2018.05.002

73. Mukherjee S, Akbar I, Kumari B, Vrati S, Basu A, Banerjee A (2019) Encephalitis Virus-induced let-7a/b interacted with the NOTCH-TLR7 pathway in microglia and facilitated neuronal death via caspase activation. International Society for Neurochemistry, Journal of Neurochemistry 149: 518-34. https://doi.org/10.1111/jnc.14645

74. O'Loughlin AJ, Woffindale CA, Wood MJ (2012) Exosomes and the emerging field of exosome-based gene therapy. Curr Gene Ther 12:262-274. https://doi.org/10.2174/156652312802083594

75. Paggetti J, Haderk F, Seiffert M, Janji B, Distler U, Ammerlaan W, Kim JY, Adam J, Lichter P, Solary E, Berchem G, Moussay E (2015) Exosomes released by chronic lymphocytic leukemia cells induce the transition of stromal cells into cancer-associated fibroblasts. Blood 126(9):1106-1117. https://doi.org/10.1182/blood-2014-12-618025

76. Pan J, Alimujiang M, Chen Q, Shi H, Luo X (2019) Exosomes derived from miR-146a-modified adipose- derived stem cells attenuate acute myocardial infarction- induced myocardial damage via downregulation of early growth response factor 1. J Cell Biochem 120:4433-4443. https://doi.org/10.1002/jcb.27731

77. Perez-Hernandez J, Forner MJ, Pinto C, Chaves FJ, Cortes R, Redon J (2015) Increased Urinary Exosomal MicroRNAs in Patients with Systemic Lupus Erythematosus. Plos One 10(9):1-16. https://doi.org/10.1371/journal.pone.0138618

78. PerezHernandez J, Olivares D, Forner MJ, Ortega A, Solaz E, Martinez F, Chaves FJ, Redon J, Cortes R (2018) Urinary exosome miR146a is a potential marker of albuminuria in essential hypertension. Journal of Translational Medicine 16:228-229. https://doi.org/10.1186/s12967-018-1604-6

79. Qian X, Xu C, Fang S, Zhao P, Wang Y, Liu H, Yuan W, Qi Z (2016) Exosomal MicroRNAs Derived From Umbilical Mesenchymal Stem Cells Inhibit Hepatitis C Virus Infection. Stem Cells Translational Medicine 5:1190-1203. https://doi.org/10.5966/sctm.2015-0348 
80. Qu Y, Zhang Q, Cai X, Li F, Ma Z, Xu M, Lu L (2017) Exosomes derived from miR-181-5p-modified adipose-derived mesenchymal stem cells prevent liver fibrosis via autophagy activation. J Cell Mol Med 21(10):2491-2502. https://doi.org/10.1111/jcmm.13170

81. Ragusa M, Barbagallo C, Statello L, Caltabiano R, Russo A, Puzzo L, Avitabile T, Longo A, Toro MD, Barbagallo D, Valadi H, Pietro CD, Purrello M, Reibaldi M (2015) miRNA profiling in vitreous humor vitreal exosomes and serum from uveal melanoma patients: Pathological and diagnostic implications. Cancer Biol Ther 16(9):1387-1396. https://doi.org/10.1080/15384047.2015.1046021

82. Roman-Canal B, Moiola CP, Gatius S, Bonnin S, Ruiz-Miró M, González E, Ojanguren A, Recuero JL, Gil-Moreno A, Falcón-Pérez JM, Ponomarenko J, Porcel JM, Matias-Guiu X, Colas E (2019) EVassociated miRNAs from pleural lavage as potential diagnostic biomarkers in lung cancer. Sci Rep 9:15057-15059. https://doi.org/10.1038/s41598-019-51578-y

83. Ruiz-de-Leon MJ, Jimenez-Sousa MA, Moreno S, Garcia M, Gutierrez-Rivas M, Leon A, MonteroAlonso M, Gonza'lez-Garcı J, Resino S, Rallo'n N, Benito JM, Vallejo A (2019) Lower expression of plasma-derived exosome miR-21 levels in HIV-1 elite controllers with decreasing CD4 T cell count. Journal of Microbiology Immunology Infection 52:667-671. https://doi.org/10.1016/j.jmii.2018.07.007

84. Sakha S, Muramatsu T, Ueda K, Inazawa J (2016) Exosomal microRNA miR-1246 induces cell motility and invasion through the regulation of DENND2D in oral squamous cell carcinoma. Sci Rep 6:38750-38711. https://doi.org/10.1038/srep38750

85. Samsonov R, Burdakov V, Shtam T, Radzhabova Z, Vasilyev D, Tsyrlina E, Titov S, Ivanov M, Berstein L, Filatov M, Kolesnikov N, Gil-Henn H, Malek A (2016) Plasma exosomal miR-21 and miR-181a differentiates follicular from papillary thyroid cancer. Tumor Biology 37:12011-12021. https://doi.org/10.1007/s13277-016-5065-3

86. Santos JC, Lima NS, Sarian LO, Matheu A, Ribeiro ML, Derchain SFM (2018) Exosome-mediated breast cancer chemoresistance via miR-155 transfer. Sci Rep 8:829-811. https://doi.org/10.1038/s41598-018-19339-5

87. Serban KA, Rezania S, Petrusca DN, Poirier C, Cao D, Justice MJ, Patel M, Tsvetkova I, Kamocki K, Mikosz A, Schweitzer KS, Jacobson S, Cardoso A, Carlesso N, Hubbard WC, Kechris K, Dragnea B, Berdyshev EV, McClintock J, Petrache I (2016) Structural and functional characterization of endothelial microparticles released by cigarette smoke. Sci Rep 6:31596-31513. https://doi.org/10.1038/srep31596

88. Shao L, Zhang Y, Lan B, Wang J, Zhang Z, Zhang L, Xiao P, Meng Q, Geng Y, Yu X, Li Y (2017) MiRNAsequence indicates that mesenchymal stem cells and exosomes have similar mechanism to enhance cardiac repair. Biomed Research International 4150705-4150709. https://doi.org/10.1155/2017/4150705

89. Shen L, Li Y, Li R, Diao Z, Yany M, Wu M, Sun H, Yan G, Hu Y, Placentaassociated serum exosomal miR155 derived from patients with preeclampsia inhibits eNOS expression in human umbilical vein 
endothelial cells. International journal of molecular medicine 41:1731-39.

https://doi.org/10.3892/ijmm.2018.3367

90. Shi Y, Wang Z, Zhu X, Chen L, Ma Y, Wang J, Yang X, Liu Z (2020) Exosomal miR-1246 in serum as a potential biomarker for early diagnosis of gastric cancer. International Journal of Clinical Oncology 25:89-99. https://doi.org/10.1007/s10147-019-01532-9

91. Solé C, Moliné T, Vidal M, Ordi-Ros J, Cortés-Hernández J (2019) An Exosomal Urinary miRNA Signature for Early Diagnosis of Renal Fibrosis in Lupus Nephritis. Cells 8:773-717. https://doi.org/10.3390/cells8080773

92. Song Y, Dou H, Li X, Zhao X, Li Y, Liu D, Ji J, Liu F, Ding L, Ni Y, Hou Y (2017) Exosomal miR-146a Contributes to the Enhanced Therapeutic Efficacy of IL-1 $\beta$-Primed Mesenchymal Stem Cells Against Sepsis. Stem Cells 35:1208-1221. https://doi.org/10.1002/stem.2564

93. Su T, Xiao Y, Xiao Y, Guo Q, Li C, Huang Y, Deng Q, Wen J, Zhou F, Luo X-H (2019) Bone marrow mesenchymal stem cells derived exosomal mir-29b-3p regulates aging-associated insulin resistance. ACS Nano 13:2450-2462. https://doi.org/10.1021/acsnano.8b09375

94. Su Z, Yuan Y, Yu M, Liu Y, Klein J, Wang XH (2018) Electrically stimulated acupuncture increases renal blood flow through exosome-carried miR-181. American Journal of Physiology-Renal Physiology 315(6):1542-1549. https://doi.org/10.1152/ajprenal.00259.2018

95. Suehiro T, Miyaaki H, Kanda Y, Shibata H, Honda T, Ozawa E, Miuma S, Taura N, Nakao K (2018) Serum exosomal microRNA122 and microRNA21 as predictive biomarkers in transarterial chemoembolizationtreated hepatocellular carcinoma patients. Oncology Letters 16:3267-3273. https://doi.org/10.3892/ol.2018.8991

96. Sun L, Liu X, Pan B, Hu X, Zhu Y, Su Y, Guo Z, Zhang G, Xu M, Xu X, Sun H, Wang S (2020) Serum exosomal miR-122 as a potential diagnostic and prognostic biomarker of colorectal cancer with liver metastasis. J Cancer 11:630-637. https://doi.org/10.7150/jca.33022

97. Sun L, Zhu M, Feng W, Lin Y, Yin J, Jin J, Wang Y (2019) Exosomal miRNA Let-7 from Menstrual Blood-Derived Endometrial Stem Cells Alleviates Pulmonary Fibrosis through Regulating Mitochondrial DNA Damage. Oxidative Medicine Cellular Longevity 4506303-4506317. https://doi.org/10.1155/2019/4506303

98. Taghikhani A, Hassan ZM, Ebrahimi M, Moazzeni SM (2018) microRNA modified tumor-derived exosomes as novel tools for maturation of dendritic cells. J Cell Physiol 1-11. https://doi.org/10.1002/jcp.27626

99. Tangtanatakul P, Klinchanhom S, Sodsai P, Sutichet T, Promjeen C, Avihingsanon Y, Hirankarn N (2019) Down-regulation of let-7a and miR-21 in urine exosomes from lupus nephritis patients during disease flare. Asian Pac J Allergy Immunol 37:189-197. https://doi.org/10.12932/ap-130318-0280

100. Thulin P, Hornby RJ, Auli M, NordahI G, Antoine DJ, Lewis PS, Goldring CE, Park BK, Prats N, Glinghammar B, Schuppe-Koistinen I (2016) A longitudinal assessment of miR-122 and GLDH as biomarkers of drug-induced liver injury in the rat. Biomarkers 22(5):461-469. https://doi.org/10.1080/1354750x.2016.1269131 
101. Tsukamoto M, linuma H, Yagi T, Matsuda K, Hashiguchi Y (2017) Circulating Exosomal MicroRNA-21 as a Biomarker in Each Tumor Stage of Colorectal Cancer. Oncology 92:360-370.

https://doi.org/10.1159/000463387

102. Uen Y, Wang JW, Wang C, Jhang Y, Chung JY, Tseng T, Sheu M, Lee S (2018) Mining of potential microRNAs with clinical correlation - regulation of syndecan-1 expression by miR-122-5p altered mobility of breast cancer cells and possible correlation with liver injury. Oncotarget 9(46):2816528175. https://doi.org/10.18632/oncotarget.25589

103. Vallabhaneni KC, Penfornis P, Dhule S, Guillonneau F, Adams KV, Mo YY, Xu R, Liu Y, Watabe K, Vemuri MC, Pochampally R (2015) Extracellular vesicles from bone marrow mesenchymal stem/stromal cells transport tumor regulatory microRNAp roteins, and metabolites. Oncotarget 6(7):4953-4967. https://doi.org/10.18632/oncotarget.3211

104. Veirman KD, Wang J, Xu S, Leleu X, Himpe E, Maes K, Bruyne ED, Valckenborgh EV, Vanderkerken K, Menu E, Riet IV (2016) Induction of miR-146a by multiple myeloma cells in mesenchymal stromal cells stimulates their pro-tumoral activity. Cancer Lett 377:17-24.

https://doi.org/10.1016/j.canlet.2016.04.024

105. Vignard V, Labbe M, Marec N, Andre-Gregoire G, Jouand N, Fonteneau JF, Labarrière N, Fradin D (2020) MicroRNAs in Tumor Exosomes Drive Immune Escape in Melanoma. Cancer Immunol Res 8(2):255-256. https://doi.org/10.1158/2326-6066.cir-19-0522

106. Wang JJ, Wang ZY, Chen R, Xiong J, Yao YL, Wu JH, Li G-X (2015) Macrophage-secreted Exosomes Delivering miRNA-21, Inhibitor can Regulate BGC-823 Cell Proliferation. Asian Pac J Cancer Prev 16(10):4203-4209. https://doi.org/10.7314/apjcp.2015.16.10.4203

107. Wang K, Jiang Z, Webster KA, Chen J, Hu H, Zhou Y, Zhao J, Wang L, Wang Y, Zhong Z, Ni C, Li Q, Xiang C, Zhang L, Wu R, Zhu W, Yu H, Hu X, Wang JA (2016) Enhanced Cardioprotection by Human Endometrium Mesenchymal Stem Cells Driven by Exosomal MicroRNA-21. Stem Cells Translational Medicine 5:1-14. https://doi.org/10.5966/sctm.2015-0386

108. Wang M, Qiu R, Yu S, Xu X, Li G, Gu R, Tan C, Zhu W, Shen B (2019) Paclitaxel-resistant gastric cancer MGC-803 cells promote epithelial-to-mesenchymal transition and chemoresistance in paclitaxel-sensitive cells via exosomal delivery of miR-155-5p. Int J Oncol 54:326-338.

https://doi.org/10.3892/ijo.2018.4601

109. Wang N, Wang L, Yang Y, Gong L, Xiao B, Liu X, A serum exosomal microRNA panel as a potential biomarker test for gastric cancer. Biochemical and Biophysical Research Communications 1-7. https://doi.org/10.1016/j.bbrc.2017.10.003

110. Wang Y, Zhang C, Zhang P, Guo G, Jiang T, Zhao X, Jiang J, Huang X, Tong H, Tian Y (2018) Serum exosomal microRNAs combined with alpha feto protein as diagnostic markers of hepatocellular carcinoma. Cancer Med 7(5):1670-1679. https://doi.org/10.1002/cam4.1390

111. Wang Y, Zhang L, Li Y, Chen L, Wang X, Guo W, Zhang X, Qin G, He S, Zimmerman A, Liu Y, Kim I, Weintraub NL, Tang Y (2015) Exosomes/microvesicles from induced pluripotent stem cells deliver 
cardioprotective miRNAs and prevent cardiomyocyte apoptosis in the ischemic myocardium. Int $\mathrm{J}$ Cardiol 192:61-69. https://doi.org/10.1016/j.ijcard.2015.05.020

112. Wu H, Wang Q, Zhong H, Li L, Zhang Q, Huang Q, Yu Z (2020) Differentially expressed microRNAs in exosomes of patients with breast cancer revealed by nextgeneration sequencing. Oncol Rep 43:240250. https://doi.org/10.3892/or.2019.7401

113. Wu J, Gu J, Shen L, Fang D, Zou X, Cao Y, Wang S, Mao L (2019) MicroRNA-155 Inhibits Enterovirus A71 Infection by Targeting PICALM. International Journal of Biological Sciences 15(13):2925-2935. https://doi.org/10.7150/ijbs.36388

114. Wu M, Ouyangc Y, Wang Z, Zhang R, Huang PH, Chen C, Li H, Li P, Quinn D, Dao M, Suresh S, Sadovsky Y, Huang TJ (2017) Isolation of exosomes from whole blood by integrating acoustics and microfluidics. PNAS 114(40):1-6. https://doi.org/10.1073/pnas.1709210114

115. Wu Q, Sun S, Li Z, Yang Q, Li B, Zhu S, Wang L, Wu J, Yuan J, Wang C, Li J, Sun S (2019) Breast cancer-released exosomes trigger cancer-associated cachexia to promote tumor progression. Adipocyte 8(1):31-45. https://doi.org/10.1080/21623945.2018.1551688

116. Xiao J, Pan Y, Li XH, Yang XY, Feng YL, Tan HH, Jiang L, Feng J, Yu XY (2016) Cardiac progenitor cellderived exosomes prevent cardiomyocytes apoptosis through exosomal miR-21 by targeting PDCD4. Cell Death Dis 7(6):e2277. https://doi.org/10.1038/cddis.2016.181

117. Xie Y, Jia Y, Cuihua X, Hu F, Xue M, Xue Y (2017) Urinary Exosomal MicroRNA Profiling in Incipient Type 2 Diabetic Kidney Disease. Journal of Diabetes Research 6978984-10. https://doi.org/10.1155/2017/6978984

118. Xu Y, Luo F, Liu Y, Shi L, Lu X, Xu W, Liu Q (2015) Exosomal miR21 derived from arsenitetransformed human bronchial epithelial cells promotes cell proliferation associated with arsenite carcinogenesis. Arch Toxicol 89:1071-1082. https://doi.org/10.1007/s00204-014-1291-x

119. Xu Z, Liu X, Wang H, Li J, Dai L, Li J, Dong C (2018) Lung adenocarcinoma cell-derived exosomal miR-21 facilitates osteoclastogenesis. Gene 666:116-122. https://doi.org/10.1016/j.gene.2018.05.008

120. Yang Y, Cai Y, Zhang Y, Liu J, Xu Z (2018) Exosomes Secreted by Adipose-Derived Stem Cells Contribute to Angiogenesis of Brain Microvascular Endothelial Cells Following Oxygen-Glucose Deprivation In Vitro Through MicroRNA-181b/TRPM7 Axis. J Mol Neurosci 65:74-83. https://doi.org/10.1007/s12031-018-1071-9

121. Yeh YY, Ozer HG, Lehman AM, Maddocks K, Yu L, Johnson AJ, Byrd JC (2015) Characterization of CLL exosomes reveals a distinct microRNA signature and enhanced secretion by activation of BCR signaling. Blood 125(21):3297-3305. https://doi.org/10.1182/blood-2014-12-618470

122. Yeung CLA, Co NN, Tsuruga T, Yeung TL, Kwan SY, Leung CS, Li Y, Lu ES, Kwan K, Wong K-K, Schmandt R, Lu KH, Mok SC (2016) Exosomal transfer of stroma-derived miR21 confers paclitaxel resistance in ovarian cancer cells through targeting APAF1. Nat Commun 7:11150-11114. https://doi.org/10.1038/ncomms 11150 
123. Yoon C, Kim J, Park G, Kim S, Kim D, Hur DY, Kim B, Kim YS (2016) Delivery of miR-155 to retinal pigment epithelial cells mediated by Burkitt's lymphoma exosomes. Tumor Biology 37:313-321. https://doi.org/10.1007/s13277-015-3769-4

124. Yu B, Kim HW, Gong M, Wang J, Millard RW, Wang Y, Ashraf M, Xu M (2015) Exosomes Secreted from GATA-4 Overexpressing Mesenchymal Stem Cells Serve as a Reservoir of Anti-Apoptotic microRNAs for Cardioprotectio. Int J Cardiol 182:349-360. https://doi.org/10.1016/j.ijcard.2014.12.043

125. Yu LX, Zhang BL, Yang Y, Wang MC, Lei GL, Gao Y, Liu H, Xiao C-H, Xu J-J, Qin H, Xu X-Y, Chen Z-S, Zhang D-D, Li F-G, Zhang S-G, Liu R (2019) Exosomal microRNAs as potential biomarkers for cancer cell migration and prognosis in hepatocellular carcinoma patient-derived cell model. Oncol Rep 41:257-269. https://doi.org/10.3892/or.2018.6829

126. Yuan D, Xu J, Wang J, Pan Y, Fu J, Bai Y, Zhang J, Shao C (2016) Extracellular miR-1246 promotes lung cancer cell proliferation and enhances radio resistance by directly targeting DR5. Oncotarget 7(22):32707-22. https://doi.org/10.18632/oncotarget.9017

127. Yun J, Han SB, Kim HJ, Go S, Lee WS, Bae WK, Cho S-H, Song E-K, Lee O-J, Kim HK, Yang Y, Kwon J, Chae HB, Lee KH, Han HS (2019) Exosomal miR-181b-5p Downregulation in Ascites Serves as a Potential Diagnostic Biomarker for Gastric Cancer-associated Malignant Ascites. Journal of Gastric Cancer 19(3):301-314. https://doi.org/10.5230/jgc.2019.19.e27

128. Zhang H, Zhu M, Shan X, Zhou X, Wang T, Zhang J, Tao J, Cheng W, Chen G, Li J, Liu P, Wang Q, Zhu W (2019) A panel of seven-miRNA signature in plasma as potential biomarker for colorectal cancer diagnosis. Gene 687:246-254. https://doi.org/10.1016/j.gene.2018.11.055

129. Zhang L, Hao C, Zhai R, Wang D, Zhang J, Bao L, Li Y, Yao W (2018) Downregulation of exosomal let7a-5p in, dust exposed- workers contributes to lung, cancer development. Respir Res 19:235-238. https://doi.org/10.1186/s12931-018-0949-y

130. Zhang Z, Li Y, Geng C, Wang H, Chen W (2019) Potential Relationship between Clinical Significance and Serum Exosomal miRNAs in Patients with Multiple Myeloma. Biomed Res Int 1575468-8. https://doi.org/10.1155/2019/1575468

131. Zhou J, Li X, Wu X, Zhang T, Zhu Q, Wang X, Wang H, Wang K, Lin Y, Wang X (2018) Exosomes Released from Tumor-Associated Macrophages Transfer miRNAs That Induce a Treg/Th17 Cell Imbalance in Epithelial Ovarian Cancer. Cancer Immunol Res 6(12):1578-1592. https://doi.org/10.1158/2326-6066.cir-17-0479

132. Zhou X, Yan T, Huang C, Xu Z, Wang L, Jiang E, Wang H, Chen Y, Liu K, Shao Z, Shang Z (2018) Melanoma cell-secreted exosomal miR-155-5p induce proangiogenic switch of cancer associated fibroblasts via SOCS1/JAK2/STAT3 signaling pathway. Journal of Experimental Clinical Cancer Research 37:242-215. https://doi.org/10.1186/s13046-018-0911-3

133. Zhou Y, Ren H, Dai B, Li J, Shang L, Huang J, Shi X (2018) Hepatocellular carcinoma-derived exosomal, miRNA-21 contributes to tumor progression, by converting hepatocyte stellate cells to cancer-associated fibroblasts. Journal of Experimental Clinical Cancer Research 37:324-318. https://doi.org/10.1186/s13046-018-0965-2 
134. Zhou Y, Wang X, Sun L, Zhou L, Ma TC, Song L, Wu JG, Li JL, Ho WZ (2016) Toll-like receptor 3 activated macrophages confer anti-HCV activity to hepatocytes through exosomes. FASEB J 30(12):4132-4140. https://doi.org/10.1096/fj.201600696r

135. Zhu J, Liu B, Wang Z, Wang D, Ni H, Zhang L, Wang Y (2019) Exosomes from nicotine-stimulated macrophages accelerate atherosclerosis through miR-21-3p/PTEN mediated VSMC migration and proliferation. Theranostics 9(23):6901-6919. https://doi.org/10.7150/thno.37357

136. Zhu Z, Zhang Y, Zhang Y, Zhang H, Liu W, Zhang N, Zhang X, Zhou G, Wu L, Hua K, Ding J (2019) Exosomes derived from human umbilical cord mesenchymal stem cells accelerate growth of VK2 vaginal epithelial cells through MicroRNAs in vitro. Hum Reprod 34(2):248-260. https://doi.org/10.1093/humrep/dey344

137. Zou X, Wei J, Huang Z, Zhou X, Lu Z, Zhu W, Miao Y (2019) Identification of a six-miRNA panel in serum benefiting pancreatic cancer diagnosis. Cancer Med 8:2810-2822. https://doi.org/10.1002/cam4.2145

\section{Figures}

CELL

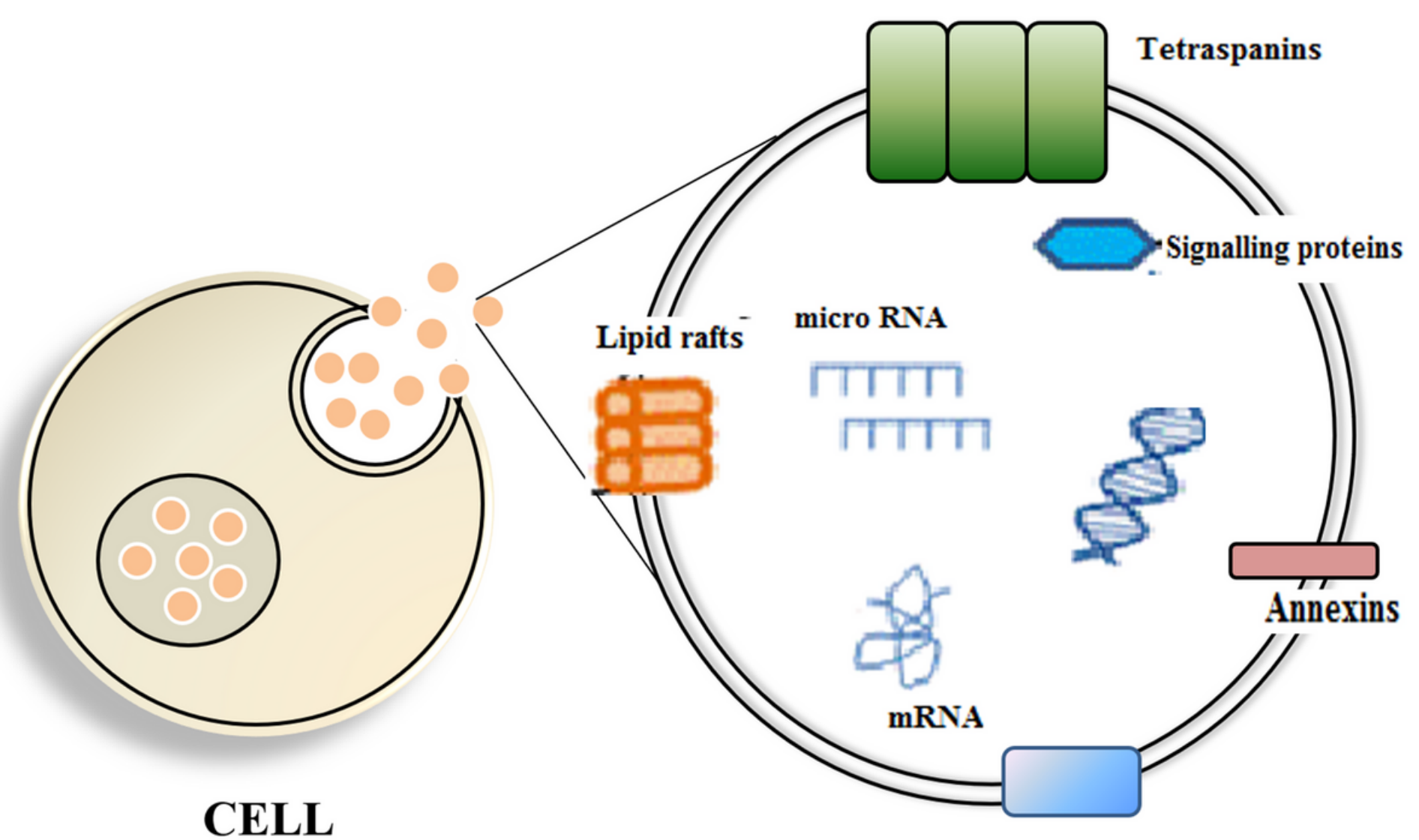

Integrins

EXOSOME

Figure 1 
Component of Exosome. Exosomes contain genetic materials such as DNA and miRNA, Tetraspanins, Lipid rafts, Annexins, Integrins, and other signaling proteins.

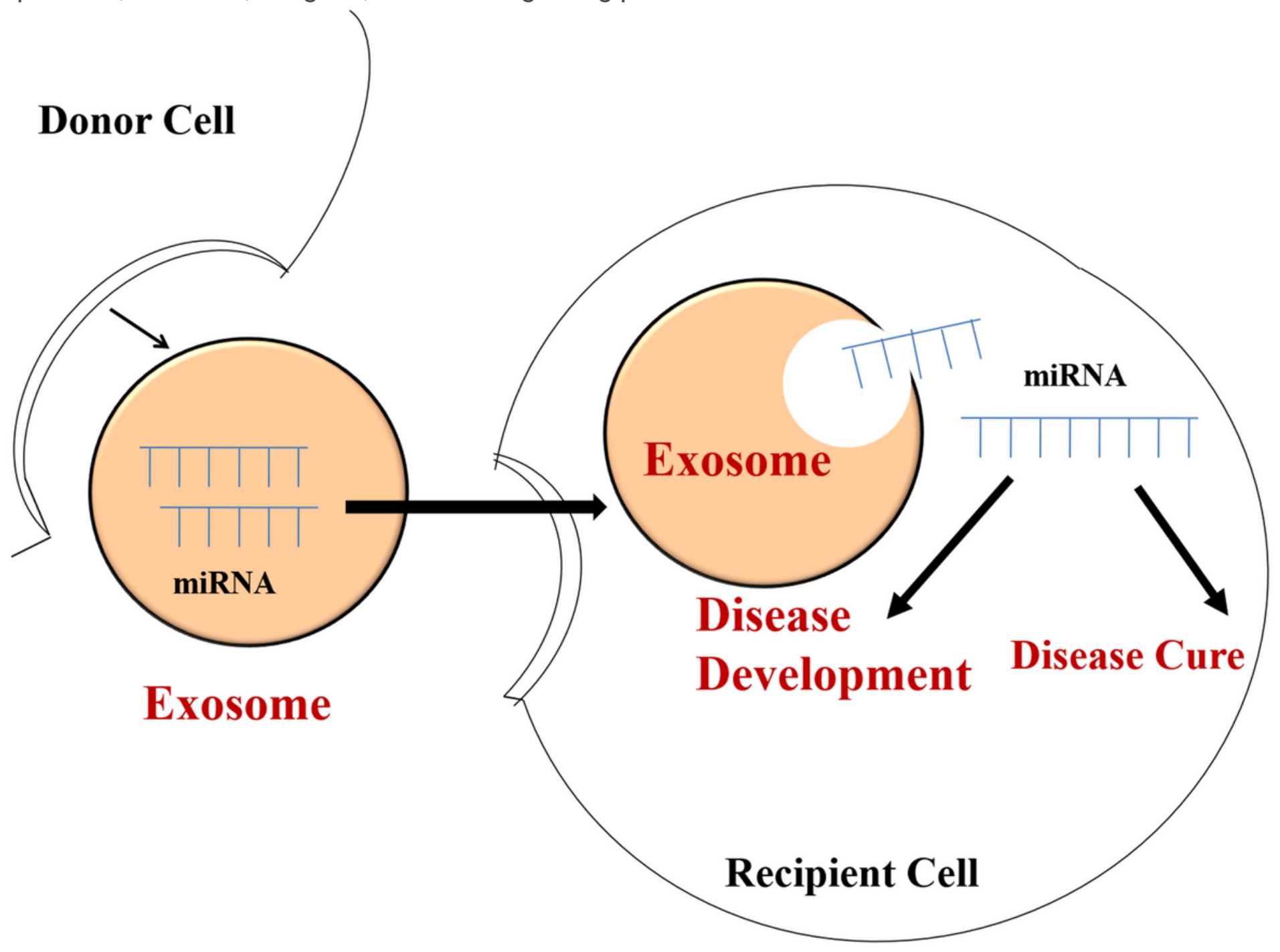

Figure 2

Cells secrete exosomes that carry different types of micro RNAs with them, as cargo, then enter into a different recipient cell where these micro RNAs being carried out via the exosomes, are released and may play role in either disease development or in disease curing.

\section{Supplementary Files}

This is a list of supplementary files associated with this preprint. Click to download.

- scan0043.pdf 